\title{
The extended Perdew-Burke-Ernzerhof functional with improved accuracy for thermodynamic and electronic properties of molecular systems
}

\author{
$\mathrm{Xin} \mathrm{Xu}^{\mathrm{a})}$ \\ State Key Laboratory for Physical Chemistry of Solid Surfaces, Center for Theoretical Chemistry, \\ Department of Chemistry, Xiamen University, Xiamen 361005, China and Materials and Process Simulation \\ Center (139-74), California Institute of Technology, Pasadena, California 91125 \\ William A. Goddard III ${ }^{\text {b) }}$ \\ Materials and Process Simulation Center (139-74), California Institute of Technology, \\ Pasadena, California 91125
}

(Received 8 July 2003; accepted 18 May 2004)

\begin{abstract}
Density functional theory (DFT) has become the method of choice for many applications of quantum mechanics to the study of the electronic properties of molecules and solids. Despite the enormous progress in improving the functionals, the current generation is inadequate for many important applications. As part of the quest of finding better functionals, we consider in this paper the Perdew-Burke-Ernzerhof (PBE) functional, which we believe to have the best theoretical foundation, but which leads to unacceptable errors in predicting thermochemical data (heats of formation) of molecular systems [mean absolute deviation $(\mathrm{MAD})=16.9 \mathrm{kcal} / \mathrm{mol}$ against the extended $G 2$ data set of 148 molecules]. Much improved thermochemistry is obtained with hybrid DFT methods that include part of the Hartree-Fock exchange [thus B3LYP (Becke's three parameter scheme combining Hartree-Fock exchange, Becke gradient corrected exchange functional and Lee-Yang-Parr correlational functional) with $\mathrm{MAD}=3.1 \mathrm{kcal} / \mathrm{mol}$ and PBE0 (Perdew's hybrid scheme using PBE exchange and correlation functionals) with $\mathrm{MAD}=4.8 \mathrm{kcal} / \mathrm{mol}]$. However we wish to continue the quest for a pure density-based DFT. Thus we optimized the four free parameters $(\mu, \kappa, \alpha$, and $\beta)$ in PBE theory against experimental atomic data and the van der Waals interaction properties of $\mathrm{Ne}_{2}$, leading to the $x P B E$ extended functional, which significantly outperforms PBE for thermochemical properties MAD reduced to $8.0 \mathrm{kcal} / \mathrm{mol}$ while being competitive or better than PBE for predictions of geometric parameters, ionization potentials, electron affinities, and proton affinities and for the description of van der Waals and hydrogen bond interactions. Thus XPBE significantly enlarges the field of applications available for pure DFT. The functional forms thus obtained for the exchange and correlational functionals may be useful for discovering new improved functionals or formalisms. (C) 2004 American Institute of Physics. [DOI: 10.1063/1.1771632]
\end{abstract}

\section{INTRODUCTION}

Density functional theory ${ }^{1}$ (DFT) has become a valuable alternative to the conventional Hartree-Fock (HF) and post-HF methods ${ }^{2}$ for the study of molecular electronic structures. DFT replaces the conventional $a b$ initio wave function, which depends on $4 N$ variables (three spatial and one spin variable for each of the $N$ electrons), by the electron density, which depends only on the three spatial variables, as a means to reach a solution to the Schrödinger equation in DFT. In principle, DFT takes into full account all many-body effects with computation costs comparable with mean field (Hartree) approximations. ${ }^{1}$ Unfortunately, the exact density functional is unknown, making it necessary to develop approximate functionals using theory to help to specify limits and functional forms and comparisons to accurate experiments to determine a limited set of parameters. Therefore, the quest of finding better and better functionals is at the heart of density functional theory.

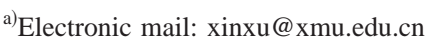

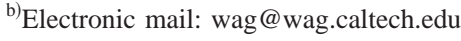

Many approximations to the exchange-correlation energy have been developed and tested. The simplest approximation is the local density approximation (LDA) based on fitting the exact numerical results from the uniform electron gas (UEG) ${ }^{3-5}$ While LDA yields results of good or moderate accuracy for some properties (lattice constants, bulk moduli, equilibrium geometries, and vibrational frequencies) (Ref. 6) the severe overbinding of LDA [mean absolute deviation $(\mathrm{MAD})=90.9 \mathrm{kcal} / \mathrm{mol}$ for the $G 2$ data set of 148 atoms and molecules] makes corrections depending on the density derivatives essential. ${ }^{7}$ The generalized gradient approximations (GGAs) use exchange functionals including the first-order gradients ${ }^{8}$ and have demonstrated great improvement over LDA for bond energies of molecules, the cohesive energies of solids, and the energy barriers for molecular reactions, but they generally remain inadequate for thermochemistry for molecules.

Several GGA functionals ${ }^{8-22}$ have proved useful in applications to molecules and solids, but Perdew, Burke, and Ernzerhof [PBE (Ref. 11)] have developed a simplified GGA that best fulfills many of the physical and mathematical requirements of DFT. In particular, PBE (a) satisfies the Lieb- 
Oxford bound ${ }^{23}$ (that is, $E_{x}[\rho] \geqslant E_{\mathrm{xc}}[\rho]$ $\left.\geqslant-1.679 \int d^{3} r \rho(r)^{4 / 3}\right)$; (b) provides the correct linear response of the uniform electron gas with proper uniform scaling ${ }^{24}$ and (c) leads to smooth pseudopotentials. ${ }^{11}$

However, the numerical performance of PBE is unsatisfactory for total atomic energies and thermochemical properties of molecular systems. ${ }^{12}$ For example, Handy and coworkers designed a test of 93 chemical systems that DFT methods should satisfy to be recommended for chemistry and concluded PBE does not pass. ${ }^{25}$

The most successful DFT functionals for thermochemistry [e.g., B3LYP (Ref. 26) and PBE (Ref. 21)] include in the exchange energy a component of exact Hartree-Fock exchange (using Kohn-Sham orbitals); however, this comes at considerable computational cost (particularly for infinite systems), which we wish to avoid, and these hybrid methods violate the spirit of DFT that the energy expression depends only on the local density.

We present here an extension of the PBE functional (denoted as XPBE) in which we optimize four parameters $(\mu, \kappa$, $\alpha$, and $\beta$ ) in PBE against (a) experimental atomic data and (b) the van der Waals interaction properties of $\mathrm{Ne}_{2}$, (c) but using no other molecular data. We find that the XPBE extended functional significantly outperforms PBE in predicting (i) atomic data (exchange energies, correlation energies, and total energies for atoms from $\mathrm{H}$ to $\mathrm{Ar}$ ) and (ii) thermochemistry (heats of formation for the extended $G 2$ set). ${ }^{27,28}$ At the same time, xPBE is competitive or of better quality than PBE in the predictions of (1) geometric parameters, ionization potentials, electron affinities, and proton affinities (against the extended G2 set) (Refs. 27 and 29), and (2) van der Waals and (3) hydrogen bond interactions, thus greatly enlarging the original field of applications.

\section{THEORETICAL BACKGROUND}

\section{A. GGA exchange and correlation functional}

In the Kohn-Sham formalism for DFT, the total energy is written as

$$
E=\mathrm{KE}+\mathrm{CE}+E_{\mathrm{xc}}
$$

where KE is the kinetic energy of the Kohn-Sham orbitals, $\mathrm{CE}$ is the classical Coulomb interaction energy for the total density constructed from the Kohn-Sham orbitals, and the exchange-correlation functional $E_{\mathrm{xc}}$, includes everything else. The challenge is to describe the $E_{\mathrm{xc}}$ term, which, conventionally, is assumed that to be separable,

$$
E_{\mathrm{xc}}=E_{x}+E_{c} \text {. }
$$

In $\mathrm{GGA}^{8}{ }^{8}$ the exchange functional is expressed as

$$
E_{x}^{\mathrm{GGA}}=\int d^{3} r \rho(r) \epsilon_{x}^{\mathrm{unif}}(\rho) F_{x}(s),
$$

where $\rho(r)$ is the total density; $\epsilon_{x}^{\text {unif }}=-3 k_{F}(/ 4 \pi)$ is the Slater exchange energy density in the uniform electron gas approximation, ${ }^{3,4} k_{F}=\left[3 \pi^{2} \rho(r)\right]^{1 / 3}$ is the local Fermi wave vector, and $F_{x}(s)$ is the GGA enhancement factor depending on a dimensionless density gradient $s$, which is defined as $s$ $=|\nabla \rho| /\left(2 k_{F} \rho\right)$.
The GGA (Ref. 17) correlation functional is expressed as

$$
E_{c}^{\mathrm{GGA}}\left[\rho^{\uparrow} \rho^{\downarrow}\right]=\int d^{3} r \rho(r)\left[\epsilon_{c}^{\mathrm{unif}}\left(r_{s}, \zeta\right)+H\left(r_{s}, \zeta, t\right)\right],
$$

where $r_{s}$ is the local Seitz radius defined as $r_{s}$ $=[(4 \pi / 3) \rho(r)]^{1 / 3}, \zeta=\left(\rho^{\uparrow}-\rho^{\downarrow}\right) / \rho$ is the relative spin polarization, and $t=|\nabla \rho| /\left(2 g k_{s} \rho\right)$ is another scaled density gradient. Here $g=\left[(1+\zeta)^{2 / 3}+(1-\zeta)^{2 / 3}\right] / 2$ is a spin-scaling factor and $k_{s}=\left(4 k_{F} / \pi\right)^{1 / 2}$ is the Thomas-Fermi screening wave vector.

Similar to Eq. (3), we may express Eq. (4) as

$$
E_{c}^{\mathrm{GGA}}=\int d^{3} r \rho(r) \epsilon_{c}^{\mathrm{unif}}(\rho) F_{c}\left(r_{s}, \zeta, t\right) .
$$

Thus we define

$$
F_{c}\left(r_{s}, \zeta, t\right) \equiv 1+\frac{H\left(r_{s}, \zeta, t\right)}{\epsilon_{c}^{\text {unif }}\left(r_{s}, \zeta\right)} .
$$

Conventionally, we may define the enhancement factor $F_{\text {xc }}$ over local exchange ${ }^{11}$

$$
E_{\mathrm{XC}}^{\mathrm{GGA}}=\int d^{3} r \rho(r) \epsilon_{x}^{\mathrm{unif}}(\rho) F_{\mathrm{xc}}\left(r_{s}, \zeta, s\right) .
$$

Thus we have

$$
F_{\mathrm{xc}}\left(r_{s}, \zeta, s\right) \equiv F_{x}(s)+\frac{\epsilon_{c}^{\mathrm{unif}}\left(r_{s}, \zeta\right)}{\epsilon_{x}^{\mathrm{unif}}(\rho)} F_{c}\left(r_{s}, \zeta, t\right) .
$$

In the well-established Perdew-Wang-91 correlation functional [PW91 (Ref. 17)], $H$ is expanded as

$$
H=H_{0}+H_{1},
$$

where

$$
\begin{aligned}
H_{0}= & g^{3} \frac{\beta^{2}}{2 \alpha} \ln \left[1+\frac{2 \alpha}{\beta} \frac{t^{2}+A t^{4}}{1+A t^{2}+A^{2} t^{4}}\right], \\
H_{1}= & \left(\frac{16}{\pi}\right)\left(3 \pi^{2}\right)^{1 / 3}\left[C_{c}\left(r_{s}\right)-C_{c}(0)-\frac{3 C_{X}}{7}\right] g^{3} t^{2} \\
& \times \exp \left[-100 g^{4} t^{2}\left(\frac{k_{s}^{2}}{k_{F}^{2}}\right)\right],
\end{aligned}
$$

with parameters $A=2 \alpha /\left(\beta\left(\exp \left[-2 \alpha \epsilon_{c}^{\text {unif }}\left(r_{s}, \zeta\right) /\left(g^{3} \beta^{2}\right)\right]\right.\right.$ $-1)), \alpha=0.09, \beta=0.066725$, the Rasolt and Geldart constants $C_{c}$ (Ref. 30) and the Sham coefficient $C_{X} \cdot{ }^{31}$

\section{B. The PBE exchange and correlation functional}

In PBE, the enhancement factor of the exchange functional takes the form

$$
F_{x}^{\mathrm{PBE}}(s)=1+\kappa-\frac{\kappa}{\left(1+\frac{\mu}{\kappa} s^{2}\right)},
$$

where $\kappa=0.804$ is set to the maximum value allowed by the local Lieb-Oxford bound ${ }^{24}$ on $E_{\mathrm{xc}}$ and $\mu=0.21951$ is set to 
recover the linear response of the uniform gas such that the effective gradient coefficient for exchange cancels that for correlation.

In the PBE correlation functional, only the first term in the PW91 correlation functional is kept:

$$
H^{\mathrm{PBE}}=H_{0}=g^{3} \frac{\beta^{2}}{2 \alpha} \ln \left[1+\frac{2 \alpha}{\beta} \frac{t^{2}+A t^{4}}{1+A t^{2}+A^{2} t^{4}}\right] .
$$

This was derived from three limits,

$$
\begin{aligned}
& H^{\mathrm{PBE}} \rightarrow \beta g^{3} t^{2} \quad(\text { as } t \rightarrow 0), \\
& H^{\mathrm{PBE}} \rightarrow-\epsilon_{C}^{\text {unif }} \quad(\text { as } t \rightarrow \infty),
\end{aligned}
$$

and

$$
E_{C}^{\mathrm{PBE}}\left[\rho_{\gamma}^{\uparrow}, \rho_{\gamma}^{\downarrow}\right] \rightarrow \text { const } \quad(\gamma \rightarrow \infty),
$$

where $\rho_{\gamma}(r)=\gamma^{3} \rho(\gamma r)$ is a uniformly scaled density. ${ }^{24}$ Note that the last constraint is violated by PW91 because of $H_{1}$ term.

In addition PBE uses $\alpha=0.0716$ instead of $\alpha=0.09$ used in PW91.

\section{THE EXTENDED PBE FUNCTIONAL: XPBE}

\section{A. The $\mu$ term}

Taking a Taylor series expansion of the PBE exchange functional around $s=0$ leads to

$$
F_{x}^{\mathrm{PBE}}(s)=1+\mu s^{2}-\frac{\mu^{2}}{\kappa} s^{4}+\cdots,
$$

PBE chooses $\mu=0.21951$ based on a theoretical analysis. ${ }^{11}$ However, there are alternative theoretical deductions of $\mu .^{31-38}$ Based on wave-vector analysis, $\mu$ was determined as $\frac{10}{81}=0.12346$ in the slowly varying limit. ${ }^{31}$ Very recently, Hirao and co-workers arrived at $\mu=\frac{20}{81}=0.24692$, and suggested that the previous value of $\frac{10}{81}$ might have been incorrect. ${ }^{38} \mu$ has also been empirically determined by fitting to certain set of the experimental data. For example, the popular Becke88 functional uses $\mu=0.27429 .{ }^{9}$ Becke was the first to propose using the exchange functional of Eq. (12), where in B86 the parameters $\mu=0.23511$ and $\kappa=0.9672$ were determined by a least squares fit to the Hartree-Fock exchange energies of the 20 atomic systems $\mathrm{H}$ through Ar, plus $\mathrm{Kr}$ and Xe. ${ }^{15}$

\section{B. The $\kappa$ term}

Perdew, Burke, and Wang ${ }^{39}$ compared the PBE enhancement factor of Eq. (12) with various numerical results for $F_{x}(s)$ as a function of $s$ in the physical range $0 \leqslant s \leqslant 3$. They showed that a sharp radial cutoff corresponds well to $\kappa=0.804$, while a more diffuse cutoff leads to a smaller value of $\kappa$. This uncertainty is also reflected in the PBE derivation of Eq. (12), in which $\kappa$ is set to the maximum value of the local Lieb-Oxford bound. ${ }^{11}$ Lacks and Gordon argued that the local Lieb-Oxford bound is not a necessary criterion for an exchange functional. ${ }^{40}$ Zhang and Yang [revPBE (Ref. 12)] relaxed this constraint and optimized $\kappa$ by fitting the exchange-only total atomic energies from He to
TABLE I. The $\{\mu, \kappa, \alpha, \beta\}$ parameters for the functionals in the PBE family. For definitions of the parameters see Eqs. (11) and (12).

\begin{tabular}{lllll}
\hline \hline & \multicolumn{1}{c}{ PBE } & revPBE & B86PBE & \multicolumn{1}{c}{ xPBE } \\
\hline$\kappa$ & 0.804 & 1.245 & 0.9672 & 0.91954 \\
$\mu$ & 0.21951 & 0.21951 & 0.23511 & 0.23214 \\
$\alpha$ & 0.0716 & 0.0716 & 0.0716 & 0.197363 \\
$\beta$ & 0.066725 & 0.066725 & 0.066725 & 0.089809 \\
\hline \hline
\end{tabular}

Ar to the exact exchange-only results from the optimized exchange potential method, ${ }^{41}$ obtaining $\kappa=1.245 .^{12}$

\section{The $\beta$ and $\alpha$ terms}

The $\mu$ in the PBE exchange functional is correlated with the $\beta$ in the PBE correlation functional. ${ }^{11}$ Any change of $\mu$ might require a related change in $\beta$ to preserve a good LSD (local spin density approximation) description of the exchange-correlation energy in the linear response of the uniform gas. We consider that there is some flexibility for optimizing the $\alpha[\alpha=0.0716$ in PBE (Ref. 11) and $\alpha=0.09$ in PW91 (Ref. 17)].

\section{Optimization}

We will treat the $\mu$ and $\kappa$ parameters in the PBE exchange functional and the $\alpha$ and $\beta$ parameters in the PBE correlation functional as four parameters to be optimized. To optimize these parameters we will fit data of the following three subsets: (1) the Hartree-Fock limit energies of 18 atoms from $\mathrm{H}$ to $\mathrm{Ar}^{42}{ }^{42}$ (2) the exact total atomic energies from $\mathrm{H}$ to $\mathrm{Ar} ;{ }^{42}$ and (3) the binding energy and bond distance of $\mathrm{Ne}_{2} .{ }^{43}$

The procedure is

$$
\boldsymbol{\nabla}=\sum_{i=1}^{n}\left(\frac{E_{i}}{E_{i}^{\mathrm{ref}}}-1\right)^{2} w_{i} .
$$

We minimize the least-square error $\boldsymbol{\nabla}$ in a self-consistent way of solving unrestricted Kohn-Sham orbital equations using aug-cc-pVTZ basis set. Here $E_{i}$ is the calculated energy and $E_{i}^{\text {ref }}$ is the corresponding reference energy ${ }^{42,43}$ in subsets (1)-(3). All energies are in atomic units. The relative weights $w_{i}$ are adjusted to give a reasonable balance of different contributions. For atomic energies, we use unit weight, except that of $\mathrm{H}$, for which we use a value of $3 \times 10^{3}$. For the binding energy of $\mathrm{Ne}_{2}$, a large weight of $3 \times 10^{7}$ is used. We optimize $\{\mu, \kappa, \alpha, \beta\}$ with $i$ running over all data in three subsets such that $n=37$ in Eq. (18). While a good fit of the calculated exchange-only total atomic energies against the data in subset (1) leads to suitable $\mu$ and $\kappa$; a good fit of the calculated exchange-correlation total atomic energies against the data of subset (2) leads to suitable $\alpha$ and $\beta$ for given $\mu$ and $\kappa$. Subset (3) provides a constraint on the optimized $\mu$, $\kappa, \alpha$, and $\beta$ for the large gradient/small density limits corresponding to large $s$ and $t$. We search $\{\mu, \kappa, \alpha, \beta\}$ sequentially to achieve a minimum in the least-square error $\boldsymbol{\nabla}$ for the whole set.

The final results for the four parameters $\{\mu, \kappa, \alpha, \beta\}$ of xPBE listed in Table I where they are compared to the values for $\mathrm{PBE}$, revPBE, and B86PBE. [Note that the notation PBE signifies that the PBE exchange functional is combined with 


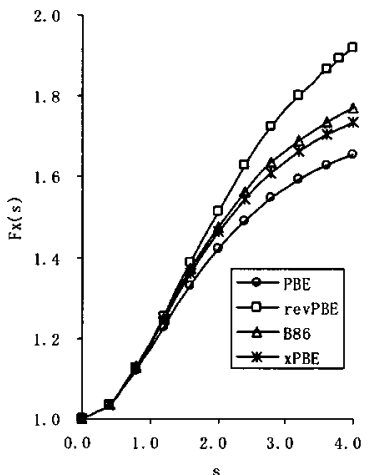

(a)

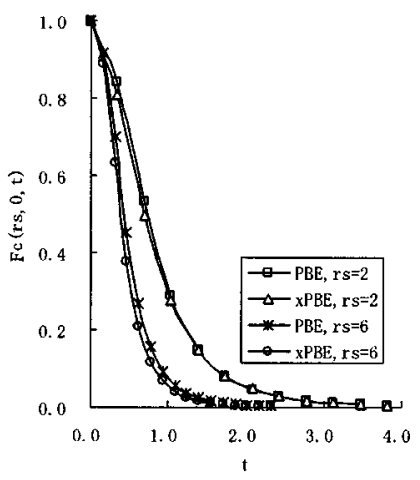

(b)
FIG. 1. (a) The enhancement factor $F_{x}(s)$, Eq. (12), for the exchange functionals in the PBE family. For all curves the $s \rightarrow 0$ asymptote is 1.0 , recovering the LSD limit. The $s \rightarrow \infty$ asymptotes are $1+\kappa=1.804$ (PBE), 2.245 (revPBE), 1.9672 (B86), and 1.91954 (xPBE). (b) shows the enhancement factor $F_{c}\left(r_{s}, \zeta, t\right)$, Eq. (6), for the correlation functionals in the PBE family for a spin-unpolarized $(\zeta=0)$ case with $r_{s}=2$ and 6 . For all curves the $t$ $\rightarrow 0$ asymptote is 1.0 , recovering the LSD limit. The $t \rightarrow \infty$ asymptote is 0.0 , with correlation effects vanishing.

the PBE correlation functional; $\mathrm{xPBE}$ indicates our extended PBE exchange functional combined with our extended PBE correlation functional; while revPBE and B86PBE share the same correlation functional with PBE.] We find the follow- ing: (a) $\alpha=0.197363$ is more than twice of the PBE $[0.0716$ (Ref. 11)] and PW91 [0.09 (Ref. 17)] values, (b) $\beta=0.089809$ is $1 / 3$ times larger than PBE [0.066 725 (Ref. 11)]. (c) $\mu=0.23214$ is somewhat larger than that in PBE (0.21951), nearly twice the theoretical value [0.123 46 (Ref. 31)] but quite close to the theoretical value found by Hirao [0.24692 (Ref. 38)] and to that proposed in B86 [0.235 11 (Ref. 15)], (d) $\kappa=0.91954$ is in between the value in PBE [0.804 (Ref. 11)] and that in B86 [0.9672 (Ref. 15)].

The final functional forms for $F_{x}^{\mathrm{xPBE}}(s), F_{c}^{\mathrm{xPBE}}\left(r_{s}, \zeta\right.$ $=0, t)$ and $F_{\mathrm{xc}}^{\mathrm{xPBE}}\left(r_{s}, \zeta=0, s\right)$ are shown in Figs. 1, and 2, respectively. Figure 1(a) represents the enhancement factor $F_{x}(s)$, Eq. (12), for the exchange functionals in the PBE family. The $s \rightarrow 0$ asymptote for all curves is 1.0, recovering the LSD limit. The $s \rightarrow \infty$ asymptotes are $1+\kappa=1.804$ (PBE), 2.245 (revPBE), 1.9672 (B86), and 1.91954 (xPBE) such that the latter three do not support the local interpretation of the global Lieb-Oxford bound. ${ }^{1,24}$ Figure 1(b) shows the enhancement factor $F_{c}\left(r_{s}, \zeta, t\right)$, Eq. (6), for the correlation functionals in the PBE family for a spin-unpolarized $(\zeta=0)$ case with $r_{s}=2$ and 6 . The $t \rightarrow 0$ asymptote for all curves is 1.0 , recovering the LSD limit. The $t \rightarrow \infty$ asymptote is 0.0 such that the correlation effects vanish. Figure 2 depicts the enhancement factor $F_{\mathrm{xc}}\left(r_{s}, \zeta, s\right)$, Eq. (8), for the functionals in the PBE family. The $s \rightarrow 0$ asymptotes for all curves are
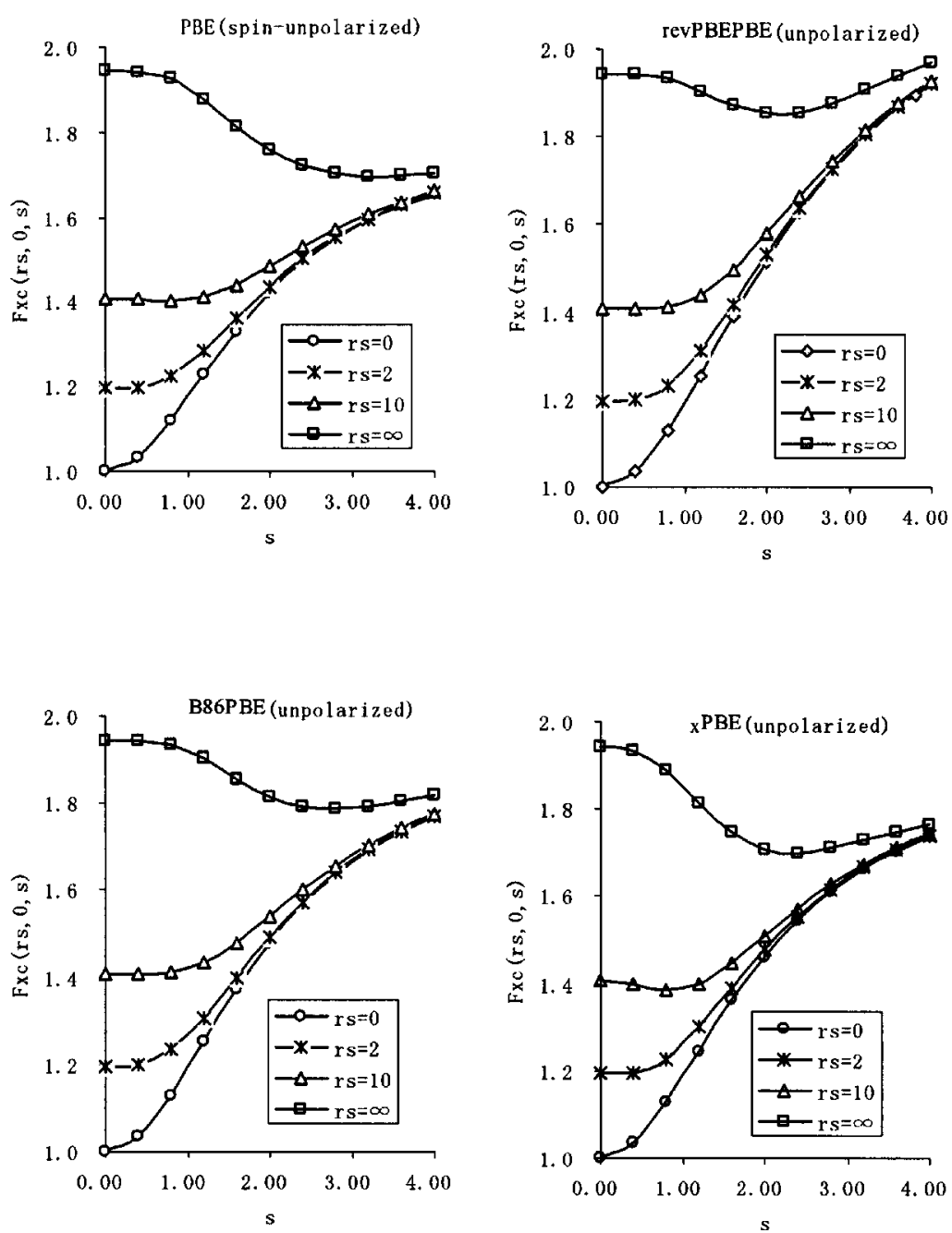

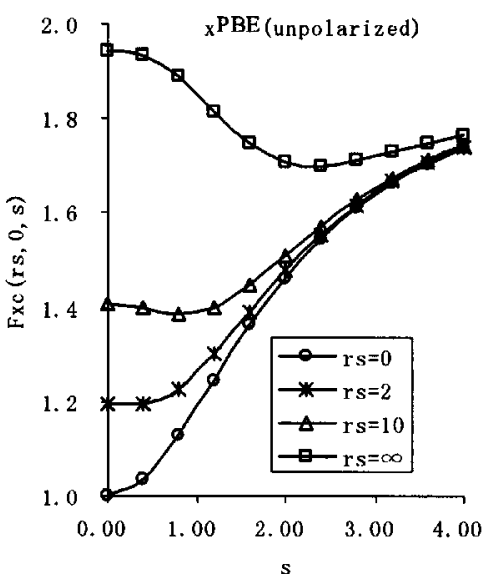

FIG. 2. The enhancement factor $F_{\mathrm{xc}}\left(r_{s}, \zeta, s\right)$, Eq. (8), for the functionals in the PBE family. For all curves the $s \rightarrow 0$ asymptotes are 1.0 for $r_{s}=0.0,1.2$ for $r_{s}=2.0$, 1.4 for $r_{s}=10.0$, and 1.9 for $r_{s}=\infty$, recovering the LSD limits. The $s \rightarrow \infty$ asymptotes are $1+\kappa=1.804$ (PBE), 2.245 (revPBE), 1.9672 (B86), and 1.91954 (xPBE) such that the correlation effects vanish. The curves for the limiting cases $r_{s}=0.0$ and $r_{s}=\infty$ were generated using $r_{s}=10^{-6}$ and $r_{s}=10^{6}$ a.u., respectively. 
TABLE II. Total energies (in a.u.) of Hartree-Fock limit [HF limit (Ref. 41)] for the first 18 atoms from H to $\mathrm{Ar}$ and the differential total energies calculated self-consistently by HF and the DFT-exchange-only methods $[\Delta E=E(\mathrm{HF}$ limit $)-E(\mathrm{DFT}$ exchange only $)]$. The basis sets used are aug-cc-pVTZ. Mean absolute deviations (MAD) compared to HF limit are given in $\mathrm{kcal} / \mathrm{mol}$. The best DFT results are in boldface.

\begin{tabular}{|c|c|c|c|c|c|c|}
\hline Atom & $E$ (HF limit) & $\Delta E(\mathrm{HF})$ & $\Delta E(\mathrm{PBE})$ & $\Delta E(\operatorname{revPBE})$ & $\Delta E(\mathrm{~B} 86)$ & $\Delta E(\mathrm{xPBE})$ \\
\hline $\mathrm{H}$ & 0.5 & -0.000179 & -0.005878 & -0.001367 & -0.001850 & -0.002696 \\
\hline $\mathrm{He}$ & -2.861704 & -0.000521 & -0.010211 & 0.004762 & 0.003450 & 0.000602 \\
\hline $\mathrm{Li}$ & -7.432730 & -0.000025 & -0.023012 & 0.001744 & -0.000117 & -0.004867 \\
\hline $\mathrm{Be}$ & -14.57303 & -0.000155 & -0.029480 & 0.004756 & 0.003732 & -0.003045 \\
\hline B & -24.52906 & 0.003112 & -0.033000 & 0.011488 & 0.012630 & 0.003912 \\
\hline $\mathrm{C}$ & -37.68864 & 0.003171 & -0.038050 & 0.013133 & 0.017346 & 0.006870 \\
\hline $\mathrm{N}$ & -54.40096 & 0.000202 & -0.047800 & 0.007548 & 0.015237 & 0.003142 \\
\hline $\mathrm{O}$ & -74.80942 & 0.003563 & -0.036760 & 0.027387 & 0.040633 & 0.026651 \\
\hline $\mathrm{F}$ & -99.40932 & -0.002440 & -0.035250 & 0.032964 & 0.052431 & 0.036848 \\
\hline $\mathrm{Ne}$ & -128.54710 & -0.013827 & -0.042040 & 0.026822 & 0.052576 & 0.035561 \\
\hline $\mathrm{Na}$ & -161.85892 & -0.000883 & -0.063010 & 0.013261 & 0.043306 & 0.024278 \\
\hline $\mathrm{Mg}$ & -199.61457 & -0.001219 & -0.075340 & 0.005518 & 0.042417 & 0.021613 \\
\hline $\mathrm{Al}$ & -241.87642 & 0.002754 & -0.092970 & -0.004095 & 0.038331 & 0.015622 \\
\hline $\mathrm{Si}$ & -288.85433 & 0.002298 & -0.112260 & -0.017832 & 0.030502 & 0.005991 \\
\hline$P$ & -340.71907 & -0.002578 & -0.135610 & -0.037953 & 0.016291 & -0.009989 \\
\hline S & -397.50477 & 0.005103 & -0.146220 & -0.039430 & 0.021413 & -0.006745 \\
\hline $\mathrm{Cl}$ & -459.48172 & 0.004249 & -0.161760 & -0.050464 & 0.017349 & -0.012546 \\
\hline $\mathrm{Ar}$ & -526.81790 & -0.004548 & -0.184420 & -0.072649 & 0.002081 & -0.029504 \\
\hline MAD & $\cdots$ & 1.8 & 44.4 & 13.0 & 13.6 & 8.6 \\
\hline
\end{tabular}

1.0 for $r_{s}=0.0,1.2$ for $r_{s}=2.0,1.4$ for $r_{s}=10.0$, and 1.9 for $r_{s}=\infty$, recovering the LSD limits. As $s \rightarrow \infty$ the correlation effects vanish. Hence $F_{\mathrm{xc}}\left(r_{s}, \zeta, s\right)$ curves converge to the corresponding $F_{x}(s)$ curves. All four functionals fulfill the non-curve-crossing condition $F_{\mathrm{xc}}\left(r_{s}, s\right)<F_{\mathrm{xc}}\left(r_{s}^{\prime}, s\right)$ for $r_{s}$ $<r_{s}^{\prime}$ and the positive condition $F_{\mathrm{xc}}\left(r_{s}, \zeta, s\right)>0$, which were derived from the fundamental scaling inequality involving scaled density $\rho_{\lambda} E_{\mathrm{xc}}\left(\rho_{\lambda}\right)>\lambda E_{\mathrm{xc}}(\rho)$ for $\lambda>1 .{ }^{44}$

Note that to fulfill Eq. (16), $H_{0}$ must cancel the logarithmic singularity of $\epsilon_{C}^{\text {unif }}$ in the high density limit: $\epsilon_{c}^{\text {unif }}\left(r_{s}, \zeta\right)$ $\rightarrow g^{3}\left[\gamma \ln \left(r_{s}\right)-\omega\right]$, where $\gamma=(1-\ln 2) / \pi^{2} \approx 0.031091$ and $\omega=0.046644$, which are obtained by assuming $\zeta=0$ in PBE. In xPBE, the optimized $\alpha$ and $\beta$ lead to $\gamma=\beta^{2} /(2 \alpha)$ $=0.020432$.

Other modifications based on the PBE exchange functional [RPBE (Ref. 13) and mPBE (Ref. 14)] changed the functional form of Eq. (12), and will not be discussed here.

\section{RESULTS AND DISCUSSION}

\section{A. Atomic data}

Table II compares the total energies (in a.u.) calculated self-consistently by HF and the DFT-exchange-only methods with the total energies in the HF limit ${ }^{42}$ for the first 18 atoms from $\mathrm{H}$ to Ar. Comparing $E(\mathrm{HF})$ to $E$ (HF limit) the MAD is $1.8 \mathrm{kcal} / \mathrm{mol}$, which may be interpreted as the basis set error remaining with the aug-cc-pVTZ basis for the atomic calculations.

The PBE exchange-only (PBE) calculations lead an unacceptable error $(\mathrm{MAD}=44.4 \mathrm{kcal} / \mathrm{mol})$. The revPBE (Ref. 12) method relaxed the local Lieb-Oxford bound constraint and optimized $\kappa$ by fitting exchange-only total atomic energies from $\mathrm{He}$ to $\mathrm{Ar}$ to the exact exchange-only results from the optimized exchange potential method. ${ }^{41}$ The revPBE functional significantly improves upon $\mathrm{PBE}$, leading to
$\mathrm{MAD}=13.0 \mathrm{kcal} / \mathrm{mol}$. Becke, the first to introduce the exchange functional in Eq. (12), ${ }^{15}$ optimized $\kappa$ and $\mu$ by a least-squares fit to the Hartree-Fock exchange energies of 20 atomic systems from $\mathrm{H}$ to Ar plus $\mathrm{Kr}$ and $\mathrm{Xe} .{ }^{15}$ This B86 functional leads to much better exchange-only total energies $(\mathrm{MAD}=13.6)$ than does PBE. From Table II, we see that $x P B E(M A D=8.6 \mathrm{kcal} / \mathrm{mol})$ leads to the best performance of the various exchange functional for atomic calculations. For comparison, we also calculated the exchange-only total energies for the first 18 atoms from $\mathrm{H}$ to Ar calculated selfconsistently by B88 (Ref. 9) and PW91 (Ref. 10) exchange functionals with aug-cc-pVTZ. As compared to the HF limit, ${ }^{42} \mathrm{~B} 88$ leads to $\mathrm{MAD}=7.1$; while PW91 leads to MAD $=12.7 \mathrm{kcal} / \mathrm{mol}$.

Table III presents another way of gauging the quality of an exchange functional. Taking HF exchange energies as a reference, post-DFT calculations with $\mathrm{HF}$ densities give MAD for the exchange energies of 46.5 (PBE), 12.9 (revPBE), 11.9 (B86), and $8.6 \mathrm{kcal} / \mathrm{mol}$ (xPBE), respectively. Similar calculations lead to $\mathrm{MAD}=8.3$ (B88) and 16.1 $\mathrm{kcal} / \mathrm{mol}$ (PW91). The MAD associated with PBE is significantly larger than those of the other exchange functionals; however $\left|\Delta E_{x}(\mathrm{PBE})\right|$ increases systematically for larger atoms suggesting that the errors associated with the PBE exchange functional may be systematic.

Table IV summarizes the correlation energies for the first 18 atoms from $\mathrm{H}$ to $\mathrm{Ar}$ (Ref. 42) and the correlation energies calculated self-consistently by DFT methods. The revPBE and B86PBE functionals share the same correlation functional as does PBE. Thus the slight difference in the correlation energies among these three sets reflects the effect of different densities originating from the different exchange functionals. The PBE correlation functional gives a MAD of 12.4, while the XPBE correlation functional gives a MAD of 
TABLE III. Hartree-Fock (HF) exchange energies (in a.u.) of the first 18 atoms from $\mathrm{H}$ to $\mathrm{Ar}$ and the differential DFT exchange-only exchange energies $\left[\Delta E_{x}=E_{x}(\mathrm{HF})-E_{x}(\mathrm{DFT})\right.$ exchange only], in a.u., DFT energies are calculated with HF densities. The basis sets used are aug-cc-pVTZ. Mean absolute deviations (MADs) are given in $\mathrm{kcal} / \mathrm{mol}$. The best DFT results are in boldface.

\begin{tabular}{|c|c|c|c|c|c|}
\hline Atom & $E_{x}(\mathrm{HF})$ & $\Delta E_{x}(\mathrm{PBE})$ & $\Delta E_{x}(\mathrm{revPBE})$ & $\Delta E_{x}(\mathrm{~B} 86)$ & $\Delta E_{x}(\mathrm{xPBE})$ \\
\hline $\mathrm{H}$ & -0.312190 & -0.006528 & -0.001946 & -0.002495 & -0.003346 \\
\hline $\mathrm{He}$ & -1.025447 & -0.012149 & 0.002939 & 0.001498 & -0.001353 \\
\hline $\mathrm{Li}$ & -1.781214 & -0.023927 & 0.001011 & -0.000940 & -0.005713 \\
\hline $\mathrm{Be}$ & -2.666716 & -0.031097 & 0.003625 & 0.002303 & -0.004531 \\
\hline B & -3.759184 & -0.035166 & 0.007908 & 0.008695 & -0.000081 \\
\hline $\mathrm{C}$ & -5.066702 & -0.041857 & 0.008251 & 0.012012 & 0.001452 \\
\hline $\mathrm{N}$ & -6.604576 & -0.054357 & 0.001972 & 0.009068 & -0.003148 \\
\hline $\mathrm{O}$ & -8.204931 & -0.043737 & 0.018561 & 0.031180 & 0.017083 \\
\hline $\mathrm{F}$ & -10.031048 & -0.038310 & 0.028347 & 0.047096 & 0.031375 \\
\hline $\mathrm{Ne}$ & -12.102300 & -0.041093 & 0.029166 & 0.054070 & 0.036881 \\
\hline $\mathrm{Na}$ & -14.017379 & -0.066965 & 0.009813 & 0.039603 & 0.020606 \\
\hline $\mathrm{Mg}$ & -15.994046 & -0.079566 & 0.002201 & 0.038573 & 0.017651 \\
\hline $\mathrm{Al}$ & -18.079161 & -0.096917 & -0.009220 & 0.032816 & 0.010013 \\
\hline $\mathrm{Si}$ & -20.292187 & -0.116116 & -0.022850 & 0.025023 & 0.000395 \\
\hline $\mathrm{P}$ & -22.640536 & -0.139566 & -0.040757 & 0.012893 & -0.013547 \\
\hline S & -25.019285 & -0.151899 & -0.047844 & 0.012461 & -0.015837 \\
\hline $\mathrm{Cl}$ & -27.530263 & -0.167157 & -0.058533 & 0.008690 & -0.021859 \\
\hline $\mathrm{Ar}$ & -30.183224 & -0.188614 & -0.075523 & -0.001467 & -0.033234 \\
\hline MAD & $\ldots$ & 46.5 & 12.9 & 11.9 & 8.6 \\
\hline
\end{tabular}

$6.5 \mathrm{kcal} / \mathrm{mol}$. Similar calculations lead to MAD $=7.3$ [BLYP (Refs. 9 and 16)] and $9.1 \mathrm{kcal} / \mathrm{mol}$ [PW91 (Ref. 17)].

The exchange-correlation total atomic energies calculated self-consistently with various DFT methods of the PBE family are summarized in Table V. Each MAD is calculated relative to the exact atomic total energies. ${ }^{42}$ PBE leads to unacceptable error of $55.5 \mathrm{kcal} / \mathrm{mol}$. MAD (revPBE) $=15.4$, $\mathrm{MAD}(\mathrm{B} 86 \mathrm{PBE})=5.0$, and $\mathrm{MAD}(\mathrm{xPBE})=4.1 \mathrm{kcal} / \mathrm{mol}$. Similar calculations lead to MAD [BLYP (Refs. 9 and 16)] $=7.6$ and MAD [PW91 or GGA II (Refs. 10 and 17)]=4.9 $\mathrm{kcal} / \mathrm{mol}$. Although B86PBE, xPBE, and PW91 give the best results for the atomic calculations, there are error cancellations between the exchange part and the correlation part in these functionals.

\section{B. Bond lengths and bond angles}

Table VI summarizes the experimental geometric parameters for a set of 32 molecules gathered by Pople and co-workers ${ }^{45}$ and compares the optimization results for the various GGAs. It has long been recognized that LDA (SVWN, Slater exchange functional plus Vosko-Wilk-Nusair

TABLE IV. Correlation energies (in a.u.) for the first 18 atoms from $\mathrm{H}$ to Ar (Ref. 41) and the differential correlation energies calculated self-consistently by DFT methods $\left[\Delta E_{c}=E_{c}\right.$ (Exact) $\left.-E_{c}(\mathrm{DFT})\right]$. The basis sets used are aug-cc-pVTZ. Mean absolute deviations (MAD) are given in kcal/mol. The best DFT results are in boldface.

\begin{tabular}{|c|c|c|c|c|c|}
\hline Atom & $\Delta E_{c}($ Exact $)$ & $\Delta E_{c}(\mathrm{PBE})$ & $\Delta E_{c}(\mathrm{revPBE})$ & $\Delta E_{c}(\mathrm{~B} 86 \mathrm{PBE})$ & $\Delta E_{c}(\mathrm{xPBE})$ \\
\hline $\mathrm{H}$ & 0 & 0.00568 & 0.00570 & 0.00568 & 0.00557 \\
\hline $\mathrm{He}$ & -0.04202 & -0.00109 & -0.00104 & -0.00108 & -0.00070 \\
\hline $\mathrm{Li}$ & -0.04533 & 0.00595 & 0.00599 & 0.00598 & 0.00875 \\
\hline $\mathrm{Be}$ & -0.09436 & -0.00919 & -0.00908 & -0.00915 & -0.00546 \\
\hline B & -0.12484 & -0.01280 & -0.01268 & -0.01277 & -0.00734 \\
\hline $\mathrm{C}$ & -0.15636 & -0.01313 & -0.01299 & -0.01308 & -0.00546 \\
\hline $\mathrm{N}$ & -0.18834 & -0.01032 & -0.01015 & -0.01026 & -0.00012 \\
\hline $\mathrm{O}$ & -0.25798 & -0.02569 & -0.02552 & -0.02563 & -0.01343 \\
\hline $\mathrm{F}$ & -0.32478 & -0.03616 & -0.03595 & -0.03609 & -0.02135 \\
\hline $\mathrm{Ne}$ & -0.39120 & -0.04493 & -0.04469 & -0.04485 & -0.02722 \\
\hline $\mathrm{Na}$ & -0.39648 & -0.02628 & -0.02626 & -0.02625 & -0.00465 \\
\hline $\mathrm{Mg}$ & -0.43943 & -0.02992 & -0.02985 & -0.02988 & -0.00556 \\
\hline $\mathrm{Al}$ & -0.47058 & -0.02635 & -0.02626 & -0.02631 & 0.00168 \\
\hline $\mathrm{Si}$ & -0.50567 & -0.02276 & -0.02262 & -0.02270 & 0.00884 \\
\hline $\mathrm{P}$ & -0.54093 & -0.01625 & -0.01601 & -0.01614 & 0.01894 \\
\hline $\mathrm{S}$ & -0.60623 & -0.02366 & -0.02342 & -0.02357 & 0.01438 \\
\hline $\mathrm{Cl}$ & -0.66828 & -0.02578 & -0.02549 & -0.02568 & 0.01548 \\
\hline $\mathrm{Ar}$ & -0.72610 & -0.02233 & -0.02198 & -0.02220 & 0.02231 \\
\hline MAD & $\ldots$ & 12.4 & 12.3 & 12.3 & 6.5 \\
\hline
\end{tabular}


TABLE V. Total atomic energies (in a.u.) of the first 18 atoms from $\mathrm{H}$ to Ar. DFT energies are calculated self-consistently with aug-cc-pVTZ. The differences between the exact total atomic energies (Ref. 41) and DFT energies $[\Delta E=E($ Exact $)-E($ DFT $)]$ are given in a.u. Mean absolute deviations (MADs) are given in $\mathrm{kcal} / \mathrm{mol}$. The best DFT results are in boldface.

\begin{tabular}{|c|c|c|c|c|c|}
\hline Atom & Exact & $\Delta E(\mathrm{PBE})$ & $\Delta E($ revPBE $)$ & $\Delta E(\mathrm{~B} 86 \mathrm{PBE})$ & $\Delta E(\mathrm{xPBE})$ \\
\hline $\mathrm{H}$ & 0.5 & -0.000197 & 0.004334 & 0.003834 & 0.002572 \\
\hline $\mathrm{He}$ & -2.903724 & -0.011302 & 0.003717 & 0.002866 & -0.001908 \\
\hline $\mathrm{Li}$ & -7.478060 & -0.017063 & 0.007732 & 0.005861 & 0.001258 \\
\hline $\mathrm{Be}$ & -14.66739 & -0.038642 & -0.004289 & -0.005384 & -0.012230 \\
\hline B & -24.65390 & -0.045320 & -0.002745 & -0.001669 & -0.009983 \\
\hline $\mathrm{C}$ & -37.8450 & -0.050820 & -0.001342 & 0.002792 & -0.006385 \\
\hline $\mathrm{N}$ & -54.5898 & -0.058126 & -0.002606 & 0.004980 & -0.004629 \\
\hline $\mathrm{O}$ & -75.0674 & -0.061694 & -0.000287 & 0.012874 & 0.001686 \\
\hline $\mathrm{F}$ & -99.7341 & -0.071057 & -0.005388 & 0.013955 & 0.001941 \\
\hline $\mathrm{Ne}$ & -128.9383 & -0.086269 & -0.017169 & 0.008425 & -0.003893 \\
\hline $\mathrm{Na}$ & -162.2554 & -0.088484 & -0.012197 & 0.017857 & 0.006268 \\
\hline $\mathrm{Mg}$ & -200.054 & -0.104253 & -0.023330 & 0.013537 & 0.001192 \\
\hline $\mathrm{Al}$ & -242.347 & -0.117679 & -0.030722 & 0.011719 & -0.000328 \\
\hline $\mathrm{Si}$ & -289.360 & -0.133426 & -0.040976 & 0.007318 & -0.004385 \\
\hline $\mathrm{P}$ & -341.260 & -0.150856 & -0.052961 & 0.001146 & -0.010162 \\
\hline $\mathrm{S}$ & -398.111 & -0.168225 & -0.065079 & -0.004336 & -0.016308 \\
\hline $\mathrm{Cl}$ & -460.150 & -0.185016 & -0.077310 & -0.009657 & -0.021772 \\
\hline $\mathrm{Ar}$ & -527.544 & -0.202749 & -0.090625 & -0.016118 & -0.028132 \\
\hline MAD & $\cdots$ & 55.5 & 15.4 & 5.0 & 4.1 \\
\hline
\end{tabular}

correlation functional) frequently gives bond lengths which are too long, while this trend is unaltered with the more elaborate GGA such as BLYP. ${ }^{45}$ Our results show that functionals of the PBE family give bond lengths which are consistently long, similar to LDA (SVWN) and BLYP. For $\mathrm{H}_{2}$ the bond length $(0.741 \AA)$ is overestimated by 0.0099 (PBE), 0.0071 (revPBE), 0.0072 (B86PBE), and $0.0069 \AA$ (xPBE). For the other $25 X-\mathrm{H}$ bonds in Table VI, the bond lengths are too long by 0.0113 (PBE), 0.0123 (revPBE), 0.0110 (B86PBE), and $0.0103 \AA$ (xPBE). For bonds between nonhydrogen atoms $(X-Y)$, the situation is worse. The MADs are increased to 0.0135 (PBE), 0.0181 (revPBE), 0.0155 (B86PBE), and $0.0150 \AA$ (xPBE).

Table VI also includes 18 bond angles and dihedral angles. All four functionals lead to bond angles which are too small. An exception from this trend is $\alpha(\mathrm{OOH})$ of $\mathrm{HOOH}$, for which the optimized results are larger than the experimental value by $\sim 5^{\circ}$.

Based on the data in Table VI, we find that the MADs for the prediction of bond lengths follow xPBE $(0.012 \AA)$ $=\operatorname{PBE}(0.012)<\operatorname{B86PBE}(0.013)<\operatorname{revPBE}(0.015)$, while the MADs for the prediction of bond angles follow PBE $\left(1.728^{\circ}\right)<\mathrm{xPBE}(1.779)<\mathrm{B} 86 \mathrm{PBE}(1.809)<\operatorname{revPBE}(1.890)$.

\section{Heats of formation}

Table VII lists the experimental heats of formation (298 K) for the extended $G 2$ set of 148 molecules and compares the results for the various GGAs. ${ }^{27-28}$ The MAD deviations from experiment (theory-expt.) are presented: $\mathrm{PBE}=16.9$ $\mathrm{kcal} / \mathrm{mol}$, revPBE $=7.3, \mathrm{~B} 86 \mathrm{PBE}=7.9$ and $\mathrm{xPBE}=8.0 . \mathrm{PBE}$ leads to a MAD too high to be useful for thermochemistry, with a clear tendency to overbind (many more negative deviations than positive deviations). In PBE, the maximum negative deviation $(-50.5 \mathrm{kcal} / \mathrm{mol})$ occurs for $\mathrm{C}_{2} \mathrm{~F}_{4}$, while the maximum positive deviation $(10.1 \mathrm{kcal} / \mathrm{mol})$ occurs for $\mathrm{Si}_{2} \mathrm{H}_{6}$. The revPBE functional significantly improves the overall accuracy of PBE (MAD $=7.3 \mathrm{kcal} / \mathrm{mol})$, leading to an error distribution ranging from $-25.4\left(\mathrm{NO}_{2}\right)$ to 29.7 $\mathrm{kcal} / \mathrm{mol}\left(\mathrm{SiF}_{4}\right)$, thus overcorrecting the overbinding tendency of PBE, B86PBE, and XPBE show comparable performance, with $\mathrm{MAD} \approx 8 \mathrm{kcal} / \mathrm{mol}$ and an error distribution ranging from -32 to $19 \mathrm{kcal} / \mathrm{mol}$. In comparison, PW91 leads to $\mathrm{MAD}=17.8,{ }^{44}$ while $\mathrm{BLYP}$ leads to $\mathrm{MAD}=7.1 \mathrm{kcal} /$ mol (Ref. 28) for the extended $G 2$ set.

In PBE there is a self-correlation energy for the hydrogen atom $(3.6 \mathrm{kcal} / \mathrm{mol}$ for $\mathrm{H})$. This situation is not improved in xPBE (See Table IV). For the inorganic hydrides $\left(X_{n} H_{m}\right.$, $X=\mathrm{H}, \mathrm{Li}, \mathrm{N}, \mathrm{O}, \mathrm{F}, \mathrm{Si}, \mathrm{P} \mathrm{S}, \mathrm{Cl} ; n=1,2 ; m=1-6)$, all methods show a similar performance, with $\mathrm{MAD}=5.5(\mathrm{PBE}), 4.9$ (revPBE), 4.7 (B86PBE), and 5.4 (xPBE) for this subset.

The performance of PBE for larger hydrocarbons (No. 78-94 in Table VII) is less satisfactory. The MAD of this subset is $22.0 \mathrm{kcal} / \mathrm{mol}$, with the maximum error of -44.1 $\mathrm{kcal} / \mathrm{mol}$ for the aromatic molecule benzene. The revPBE functional performs much better, with $\mathrm{MAD}=10.7 \mathrm{kcal} / \mathrm{mol}$. The maximum error $(24.1 \mathrm{kcal} / \mathrm{mol})$ occurs at isobutane. For benzene, revPBE deviates from experiment by $6.3 \mathrm{kcal} / \mathrm{mol}$. $\mathrm{B} 86 \mathrm{PBE}(\mathrm{MAD}=5.5)$ and $\mathrm{xPBE}(\mathrm{MAD}=5.8)$ are the best for this subset, with a maximum error of $-14.7 \mathrm{kcal} / \mathrm{mol}$ at benzene.

For a subset of substituted hydrocarbons (No. 95-136 in Table VII), the performance of PBE is also less satisfactory, showing a tendency toward large overbinding. The MAD of this subset is $22.9 \mathrm{kcal} / \mathrm{mol}$, with the maximum error of $-49.9 \mathrm{kcal} / \mathrm{mol}$ for pyridine. The revPBE functional significantly improves over PBE, with the MAD being reduced to $6.8 \mathrm{kcal} / \mathrm{mol}$. The maximum error $(18.8 \mathrm{kcal} / \mathrm{mol})$ occurs at isopropanol. B86PBE and xPBE have a similar accuracy, 
TABLE VI. Experimental geometries (Ref. 45). Bond distances in angstroms, bond and dihedral angles in degrees. DFT geometries optimizations are performed with aug-cc-pVTZ $(-f)$. The best DFT results are in boldface.

\begin{tabular}{|c|c|c|c|c|c|c|c|}
\hline No. & Molecule & Geometric parameters & Expt. & PBE & revPBE & B86РBE & xPBE \\
\hline 1 & $\mathrm{H}_{2}$ & $r(\mathrm{HH})$ & 0.741 & 0.751 & 0.748 & 0.748 & 0.748 \\
\hline 2 & $\mathrm{LiH}$ & $r(\mathrm{LiH})$ & 1.595 & 1.606 & 1.612 & 1.606 & 1.605 \\
\hline 3 & $\mathrm{BeH}$ & $r(\mathrm{BeH})$ & 1.343 & 1.357 & 1.359 & 1.356 & 1.355 \\
\hline 4 & $\mathrm{CH}$ & $r(\mathrm{CH})$ & 1.120 & 1.136 & 1.138 & 1.136 & 1.135 \\
\hline \multirow[t]{2}{*}{5} & \multirow[t]{2}{*}{$\mathrm{CH}_{2}\left({ }^{3} B_{1}\right)$} & $r(\mathrm{CH})$ & 1.078 & 1.085 & 1.086 & 1.084 & 1.084 \\
\hline & & $a(\mathrm{HCH})$ & 136.0 & 135.7 & 135.1 & 135.4 & 135.4 \\
\hline \multirow[t]{2}{*}{6} & \multirow[t]{2}{*}{$\mathrm{CH}_{2}\left({ }^{1} A_{1}\right)$} & $r(\mathrm{CH})$ & 1.111 & 1.122 & 1.124 & 1.122 & 1.121 \\
\hline & & $a(\mathrm{HCH})$ & 102.4 & 100.8 & 100.7 & 100.8 & 100.8 \\
\hline 7 & $\mathrm{CH}_{3}$ & $r(\mathrm{CH})$ & 1.079 & 1.086 & 1.087 & 1.085 & 1.085 \\
\hline 8 & $\mathrm{CH}_{4}$ & $r(\mathrm{CH})$ & 1.086 & 1.096 & 1.097 & 1.096 & 1.095 \\
\hline 9 & $\mathrm{NH}$ & $r(\mathrm{NH})$ & 1.045 & 1.050 & 1.051 & 1.050 & 1.049 \\
\hline \multirow[t]{2}{*}{10} & \multirow[t]{2}{*}{$\mathrm{NH}_{2}$} & $r(\mathrm{NH})$ & 1.024 & 1.037 & 1.038 & 1.037 & 1.036 \\
\hline & & $a(\mathrm{HNH})$ & 103.4 & 102.3 & 102.1 & 102.2 & 102.3 \\
\hline \multirow[t]{2}{*}{11} & \multirow[t]{2}{*}{$\mathrm{NH}_{3}$} & $r(\mathrm{NH})$ & 1.012 & 1.023 & 1.024 & 1.023 & 1.022 \\
\hline & & $a(\mathrm{HNH})$ & 106.0 & 106.0 & 105.7 & 105.9 & 105.9 \\
\hline 12 & $\mathrm{OH}$ & $r(\mathrm{OH})$ & 0.971 & 0.985 & 0.985 & 0.984 & 0.984 \\
\hline \multirow[t]{2}{*}{13} & \multirow[t]{2}{*}{$\mathrm{H}_{2} \mathrm{O}$} & $r(\mathrm{OH})$ & 0.959 & 0.971 & 0.971 & 0.971 & 0.970 \\
\hline & & $a(\mathrm{HOH})$ & 103.9 & 104.1 & 103.9 & 104.0 & 104.1 \\
\hline 14 & $\mathrm{HF}$ & $r(\mathrm{HF})$ & 0.917 & 0.932 & 0.932 & 0.932 & 0.932 \\
\hline 15 & $\mathrm{Li}_{2}$ & $r(\mathrm{LiLi})$ & 2.670 & 2.728 & 2.750 & 2.732 & 2.733 \\
\hline 16 & $\mathrm{LiF}$ & $r(\mathrm{LiF})$ & 1.564 & 1.586 & 1.597 & 1.591 & 1.590 \\
\hline \multirow[t]{2}{*}{17} & \multirow{2}{*}{$\mathrm{C}_{2} \mathrm{H}_{2}$} & $r(\mathrm{CC})$ & 1.203 & 1.207 & 1.210 & 1.208 & 1.207 \\
\hline & & $r(\mathrm{CH})$ & 1.061 & 1.070 & 1.070 & 1.069 & 1.069 \\
\hline \multirow[t]{3}{*}{18} & $\mathrm{H}_{2} \mathrm{C}=\mathrm{CH}_{2}$ & $r(\mathrm{CC})$ & 1.339 & 1.333 & 1.337 & 1.335 & 1.334 \\
\hline & & $r(\mathrm{CH})$ & 1.085 & 1.091 & 1.092 & 1.091 & 1.090 \\
\hline & & $a(\mathrm{HCH})$ & 117.8 & 116.6 & 116.5 & 116.5 & 116.5 \\
\hline 19 & $\mathrm{H}_{3} \mathrm{C}-\mathrm{CH}_{3}$ & $r(\mathrm{CC})$ & 1.526 & 1.530 & 1.537 & 1.534 & 1.533 \\
\hline & & $r(\mathrm{CH})$ & 1.088 & 1.099 & 1.100 & 1.098 & 1.098 \\
\hline & & $a(\mathrm{HCH})$ & 107.4 & 107.6 & 107.6 & 107.6 & 107.6 \\
\hline 20 & $\mathrm{CN}$ & $r(\mathrm{CN})$ & 1.172 & 1.175 & 1.178 & 1.176 & 1.175 \\
\hline 21 & $\mathrm{HCN}$ & $r(\mathrm{CN})$ & 1.153 & 1.159 & 1.162 & 1.160 & 1.159 \\
\hline & & $r(\mathrm{CH})$ & 1.065 & 1.075 & 1.075 & 1.074 & 1.073 \\
\hline 22 & $\mathrm{CO}$ & $r(\mathrm{CO})$ & 1.128 & 1.138 & 1.141 & 1.140 & 1.139 \\
\hline 23 & $\mathrm{HCO}$ & $r(\mathrm{CO})$ & 1.117 & 1.184 & 1.188 & 1.186 & 1.185 \\
\hline & & $r(\mathrm{CH})$ & 1.110 & 1.134 & 1.135 & 1.133 & 1.132 \\
\hline & & $a(\mathrm{HCO})$ & 127.4 & 123.9 & 123.9 & 123.9 & 123.9 \\
\hline 24 & $\mathrm{H}_{2} \mathrm{C}=\mathrm{O}$ & $r(\mathrm{CO})$ & 1.208 & 1.210 & 1.214 & 1.212 & 1.212 \\
\hline & & $r(\mathrm{CH})$ & 1.116 & 1.117 & 1.118 & 1.116 & 1.116 \\
\hline & & $a(\mathrm{HCO})$ & 116.5 & 116.1 & 116.0 & 116.1 & 116.0 \\
\hline 25 & $\mathrm{CH}_{3}-\mathrm{OH}$ & $r(\mathrm{CO})$ & 1.421 & 1.431 & 1.439 & 1.437 & 1.436 \\
\hline & ( $\mathrm{H}_{a}$ in-plane, & $r\left(\mathrm{CH}_{a}\right)$ & 1.093 & 1.096 & 1.097 & 1.096 & 1.095 \\
\hline & & $r\left(\mathrm{CH}_{b}\right)$ & 1.093 & 1.103 & 1.103 & 1.102 & 1.101 \\
\hline & & $r(\mathrm{OH})$ & 0.963 & 0.970 & 0.970 & 0.970 & 0.970 \\
\hline & & $a\left(\mathrm{OCH}_{a}\right)$ & 107.0 & 106.7 & 106.6 & 106.6 & 106.6 \\
\hline & & $a(\mathrm{COH})$ & 108.0 & 107.9 & 107.6 & 107.7 & 107.8 \\
\hline & & $a\left(\mathrm{H}_{b} \mathrm{CH}_{b}\right)$ & 108.5 & 109.0 & 109.1 & 109.1 & 109.1 \\
\hline 26 & $\mathrm{~N}_{2}$ & $r(\mathrm{NN})$ & 1.098 & 1.103 & 1.106 & 1.105 & 1.104 \\
\hline 27 & $\mathrm{H}_{2} \mathrm{~N}-\mathrm{NH}_{2}$ & $r(\mathrm{NN})$ & 1.447 & 1.447 & 1.458 & 1.454 & 1.452 \\
\hline & & $r\left(\mathrm{NH}_{b}\right)$ & 1.008 & 1.025 & 1.026 & 1.025 & 1.024 \\
\hline & & $r\left(\mathrm{NH}_{a}\right)$ & 1.008 & 1.021 & 1.022 & 1.021 & 1.020 \\
\hline & & $a\left(\mathrm{NNH}_{b}\right)$ & 113.3 & 111.5 & 111.1 & 111.2 & 111.3 \\
\hline & & $a\left(\mathrm{NNH}_{a}\right)$ & 109.2 & 106.7 & 106.2 & 106.4 & 106.5 \\
\hline & & $a\left(\mathrm{H}_{a} \mathrm{NH}_{b}\right)$ & 109.2 & 106.9 & 106.5 & 106.7 & 106.8 \\
\hline & & $d\left(\mathrm{H}_{a} \mathrm{NNH}_{b}\right)$ & 88.90 & 90.40 & 90.37 & 90.44 & 90.42 \\
\hline 28 & NO & $r(\mathrm{NO})$ & 1.151 & 1.160 & 1.164 & 1.162 & 1.162 \\
\hline 29 & $\mathrm{O}_{2}$ & $r(\mathrm{OO})$ & 1.207 & 1.225 & 1.230 & 1.228 & 1.228 \\
\hline 30 & $\mathrm{HO}-\mathrm{OH}$ & $r(\mathrm{OO})$ & 1.475 & 1.468 & 1.476 & 1.475 & 1.474 \\
\hline & & $r(\mathrm{OH})$ & 0.950 & 0.977 & 0.977 & 0.977 & 0.976 \\
\hline & & $a(\mathrm{OOH})$ & 94.80 & 99.93 & 99.80 & 99.82 & 99.87 \\
\hline & & $d(\mathrm{HOOH})$ & 120.0 & 111.7 & 111.5 & 111.7 & 111.8 \\
\hline 31 & $\mathrm{~F}_{2}$ & $r(\mathrm{FF})$ & 1.417 & 1.415 & 1.422 & 1.421 & 1.421 \\
\hline 32 & $\mathrm{CO}_{2}$ & $r(\mathrm{CO})$ & 1.162 & 1.172 & 1.175 & 1.173 & 1.173 \\
\hline MAI & ance) & & $\cdots$ & 0.012 & 0.015 & 0.013 & 0.012 \\
\hline MAI & & & & 1.728 & 1.890 & 1.809 & 1.779 \\
\hline
\end{tabular}


TABLE VII. Experimental heats of formation ( $\mathrm{kcal} / \mathrm{mol} 298 \mathrm{~K}$ ) for the $G 2$ test set (148 molecules) (Refs. 27 and 28) and the deviations (theory-expt.) obtained from PBE, revPBE, B86PBE, and xPBE using aug-cc-pVTZ, basis sets. G2 geometries (Refs. 27 and 28) are used in the DFT calculations. The best DFT results are in boldface.

\begin{tabular}{|c|c|c|c|c|c|c|}
\hline No. & Molecule & Expt. & PBE & revPBE & B86PBE & xPBE \\
\hline 1 & $\mathrm{H}_{2}$ & 0.00 & 4.578 & 3.657 & 4.072 & 5.135 \\
\hline 2 & $\mathrm{LiH}$ & 33.30 & 4.455 & 4.632 & 4.244 & 5.358 \\
\hline 3 & $\mathrm{BeH}$ & 81.70 & -5.806 & -5.044 & -5.585 & -5.314 \\
\hline 4 & $\mathrm{CH}$ & 142.50 & -0.900 & 0.578 & -0.288 & 0.370 \\
\hline 5 & $\mathrm{CH}_{2}\left({ }^{3} B_{1}\right)$ & 93.70 & -4.468 & -0.722 & -2.226 & -1.571 \\
\hline 6 & $\mathrm{CH}_{2}\left({ }^{1} A_{1}\right)$ & 102.75 & 1.649 & 5.242 & 3.489 & 4.599 \\
\hline 7 & $\mathrm{CH}_{3}$ & 35.00 & -3.410 & 2.513 & -0.080 & 1.193 \\
\hline 8 & $\mathrm{CH}_{4}$ & -17.90 & -0.852 & 7.332 & 3.892 & 5.629 \\
\hline 9 & $\mathrm{NH}$ & 85.20 & -5.039 & -3.104 & -4.327 & -3.527 \\
\hline 10 & $\mathrm{NH}_{2}$ & 45.10 & -7.162 & -2.564 & -4.992 & -3.590 \\
\hline 11 & $\mathrm{NH}_{3}$ & -10.97 & -4.610 & 2.989 & -0.533 & 1.317 \\
\hline 12 & $\mathrm{OH}$ & 9.40 & -3.597 & -0.486 & -1.876 & -1.259 \\
\hline 13 & $\mathrm{H}_{2} \mathrm{O}$ & -57.80 & -2.132 & 4.463 & 1.836 & 3.004 \\
\hline 14 & $\mathrm{HF}$ & -65.14 & -1.307 & 2.584 & 1.184 & 1.720 \\
\hline 15 & $\mathrm{SiH}_{2}\left({ }^{1} A_{1}\right)$ & 65.20 & 3.541 & 5.732 & 4.723 & 6.044 \\
\hline 16 & $\mathrm{SiH}_{2}\left({ }^{3} B_{1}\right)$ & 86.20 & -0.889 & 0.708 & 0.350 & 1.326 \\
\hline 17 & $\mathrm{SiH}_{3}$ & 47.90 & 2.867 & 5.817 & 4.658 & 6.361 \\
\hline 18 & $\mathrm{SiH}_{4}$ & 8.20 & 8.185 & 12.508 & 10.624 & 12.960 \\
\hline 19 & $\mathrm{PH}_{2}$ & 33.10 & -1.845 & 0.900 & -0.243 & 1.078 \\
\hline 20 & $\mathrm{PH}_{3}$ & 1.30 & 2.358 & 6.878 & 5.088 & 6.906 \\
\hline 21 & $\mathrm{H}_{2} \mathrm{~S}$ & -4.90 & 0.335 & 4.382 & 3.048 & 4.005 \\
\hline 22 & $\mathrm{HCl}$ & -22.06 & -0.440 & 1.948 & 1.261 & 1.663 \\
\hline 23 & $\mathrm{Li}_{2}$ & 51.60 & 4.032 & 4.586 & 4.132 & 4.867 \\
\hline 24 & $\mathrm{LiF}$ & -80.10 & -1.749 & 3.352 & 0.634 & 0.946 \\
\hline 25 & $\mathrm{C}_{2} \mathrm{H}_{2}$ & 54.19 & -9.509 & 3.343 & -2.296 & -1.837 \\
\hline 26 & $\mathrm{H}_{2} \mathrm{C}=\mathrm{CH}_{2}$ & 12.54 & -9.092 & 6.147 & -0.386 & 1.073 \\
\hline 27 & $\mathrm{H}_{3} \mathrm{C}-\mathrm{CH}_{3}$ & -20.08 & -6.075 & 11.617 & 4.229 & 6.630 \\
\hline 28 & $\mathrm{CN}$ & 104.90 & -14.476 & -5.411 & -9.820 & -9.720 \\
\hline 29 & $\mathrm{HCN}$ & 31.50 & -13.436 & -2.380 & -7.615 & -7.002 \\
\hline 30 & $\mathrm{CO}$ & -26.42 & -10.309 & -0.981 & -4.945 & -4.746 \\
\hline 31 & $\mathrm{HCO}$ & 10.00 & -17.302 & -6.414 & -10.973 & -10.492 \\
\hline 32 & $\mathrm{H}_{2} \mathrm{C}=\mathrm{O}$ & -25.96 & -13.102 & -0.673 & -5.881 & -4.912 \\
\hline 33 & $\mathrm{CH}_{3}-\mathrm{OH}$ & -48.00 & -8.815 & 6.899 & 0.429 & 2.369 \\
\hline 34 & $\mathrm{~N}_{2}$ & 0.00 & -13.416 & -4.133 & -8.940 & -8.289 \\
\hline 35 & $\mathrm{H}_{2} \mathrm{~N}-\mathrm{NH}_{2}$ & 22.79 & -15.114 & 1.240 & -6.255 & -3.560 \\
\hline 36 & NO & 21.58 & -19.198 & -9.934 & -14.123 & -13.671 \\
\hline 37 & $\mathrm{O}_{2}$ & 0.00 & -22.832 & -14.032 & -17.355 & -17.192 \\
\hline 38 & $\mathrm{HO}-\mathrm{OH}$ & -32.53 & -13.597 & -0.424 & -5.790 & -4.402 \\
\hline 39 & $\mathrm{~F}_{2}$ & 0.00 & -13.398 & -6.552 & -9.194 & -9.156 \\
\hline 40 & $\mathrm{CO}_{2}$ & -94.05 & -29.093 & -11.453 & -18.573 & -18.580 \\
\hline 41 & $\mathrm{Na}_{2}$ & 33.96 & -1.087 & -0.168 & -0.953 & -0.283 \\
\hline 42 & $\mathrm{Si}_{2}$ & 139.87 & -3.769 & 0.290 & -1.203 & -1.165 \\
\hline 43 & $\mathrm{P}_{2}$ & 34.31 & -4.506 & 1.545 & -0.983 & -0.485 \\
\hline 44 & $\mathrm{~S}_{2}$ & 30.74 & -13.137 & -6.932 & -9.115 & -9.307 \\
\hline 45 & $\mathrm{Cl}_{2}$ & 0.00 & -7.044 & -1.759 & -3.559 & -3.636 \\
\hline 46 & $\mathrm{NaCl}$ & -43.56 & 2.845 & 5.526 & 4.330 & 4.866 \\
\hline 47 & $\mathrm{SiO}$ & -24.64 & -3.444 & 4.747 & 1.070 & 1.578 \\
\hline 48 & CS & 66.90 & -8.283 & -1.070 & -3.986 & -4.031 \\
\hline 49 & SO & 1.20 & -15.495 & -7.533 & -10.636 & -10.550 \\
\hline 50 & $\mathrm{ClO}$ & 24.19 & -16.727 & -9.685 & -12.442 & -12.337 \\
\hline 51 & $\mathrm{ClF}$ & -13.24 & -10.654 & -4.177 & -6.594 & -6.571 \\
\hline 52 & $\mathrm{H}_{3} \mathrm{Si}-\mathrm{SiH}_{3}$ & 19.10 & 10.137 & 20.096 & 15.979 & 19.309 \\
\hline 53 & $\mathrm{CH}_{3} \mathrm{Cl}$ & -19.56 & -6.436 & 5.009 & 0.494 & 1.559 \\
\hline 54 & $\mathrm{H}_{3} \mathrm{C}-\mathrm{SH}$ & -5.50 & -5.221 & 8.114 & 2.875 & 4.494 \\
\hline 55 & $\mathrm{HOCl}$ & -17.80 & -10.995 & -1.661 & -5.258 & -4.636 \\
\hline 56 & $\mathrm{SO}_{2}$ & -70.95 & -20.517 & -4.020 & -10.512 & -10.148 \\
\hline 57 & $\mathrm{BF}_{3}$ & -271.41 & -13.075 & 7.874 & -0.927 & -1.122 \\
\hline 58 & $\mathrm{BCl}_{3}$ & -96.30 & -15.428 & 0.757 & -5.310 & -5.979 \\
\hline 59 & $\mathrm{AlF}_{3}$ & -289.03 & 1.367 & 18.032 & 10.664 & 10.669 \\
\hline 60 & $\mathrm{AlCl}_{3}$ & -139.72 & -1.568 & 10.908 & 6.121 & 6.322 \\
\hline 61 & $\mathrm{CF}_{4}$ & -223.04 & -30.625 & -1.715 & -12.731 & -12.662 \\
\hline 62 & $\mathrm{CCl}_{4}$ & -22.94 & -22.615 & 1.143 & -7.536 & -8.367 \\
\hline 63 & $\mathrm{C}=\mathrm{O}=\mathrm{S}$ & -33.08 & -27.202 & -11.588 & -17.720 & -17.967 \\
\hline 64 & $\mathrm{CS}_{2}$ & 27.95 & -23.977 & -10.253 & -15.486 & -15.895 \\
\hline
\end{tabular}


TABLE VII. (Continued.)

\begin{tabular}{|c|c|c|c|c|c|c|}
\hline No. & Molecule & Expt. & PBE & revPBE & B86PBE & $\mathrm{xPBE}$ \\
\hline 65 & $\mathrm{COF}_{2}$ & -152.70 & -23.929 & -0.779 & -9.794 & -9.763 \\
\hline 66 & $\mathrm{SiF}_{4}$ & -385.98 & 4.403 & 29.681 & 18.995 & 19.206 \\
\hline 67 & $\mathrm{SiCl}_{4}$ & -158.40 & -3.169 & 16.345 & 9.202 & 9.202 \\
\hline 68 & $\mathrm{~N}_{2} \mathrm{O}$ & 19.61 & -39.088 & -21.781 & -29.403 & -28.833 \\
\hline 69 & CINO & 12.36 & -33.577 & -19.938 & -25.754 & -25.187 \\
\hline 70 & $\mathrm{NF}_{3}$ & -31.57 & -41.792 & -20.875 & -29.215 & -28.605 \\
\hline 71 & $\mathrm{PF}_{3}$ & -229.07 & -10.472 & 9.784 & 1.421 & 1.933 \\
\hline 72 & $\mathrm{O}_{2}$ & 34.10 & -37.418 & -20.848 & -27.340 & -26.833 \\
\hline 73 & $\mathrm{~F}_{2} \mathrm{O}$ & 5.86 & -30.002 & -16.170 & -21.638 & -21.370 \\
\hline 74 & $\mathrm{ClF}_{3}$ & -37.97 & -39.619 & -20.071 & -27.631 & -27.674 \\
\hline 75 & $\mathrm{C}_{2} \mathrm{~F}_{4}$ & -157.40 & -50.537 & -14.664 & -28.749 & -29.108 \\
\hline 76 & $\mathrm{C}_{2} \mathrm{Cl}_{4}$ & -2.97 & -36.371 & $-\mathbf{5 . 0 1 7}$ & -16.938 & -18.370 \\
\hline 77 & $\mathrm{CF}_{3} \mathrm{CN}$ & -118.40 & -44.209 & -8.216 & -23.057 & -23.055 \\
\hline 78 & $\mathrm{C}_{3} \mathrm{H}_{4}$ (propyne) & 44.20 & -16.917 & 5.596 & -3.991 & -2.917 \\
\hline 79 & $\mathrm{C}_{3} \mathrm{H}_{4}$ (allene) & 45.50 & -21.750 & 0.921 & -8.733 & -7.621 \\
\hline 80 & $\mathrm{C}_{3} \mathrm{H}_{4}$ (cyclopropene) & 66.20 & -19.823 & 3.355 & -6.088 & -5.364 \\
\hline 81 & $\mathrm{C}_{3} \mathrm{H}_{6}$ (propylene) & 4.78 & -14.665 & 10.469 & -0.150 & 1.957 \\
\hline 82 & $\mathrm{C}_{3} \mathrm{H}_{6}$ (cyclopropane) & 12.70 & -16.607 & 9.461 & -1.096 & 0.632 \\
\hline 83 & $\mathrm{C}_{3} \mathrm{H}_{6}$ (propane) & -25.00 & -10.538 & 17.102 & 5.565 & 8.643 \\
\hline 84 & $\mathrm{C}_{4} \mathrm{H}_{6}$ (butadiene) & 26.30 & -23.736 & 8.754 & -5.082 & -3.284 \\
\hline 85 & $\mathrm{C}_{4} \mathrm{H}_{6}$ (2-butyne) & 34.80 & -23.151 & 9.014 & -4.526 & -2.833 \\
\hline 86 & $\mathrm{C}_{4} \mathrm{H}_{6}$ (methylene cyclopropane) & 47.90 & -29.508 & 3.758 & -9.868 & -8.501 \\
\hline 87 & $\mathrm{C}_{4} \mathrm{H}_{6}$ (bicyclobutane) & 51.90 & -26.259 & 8.069 & -5.547 & -4.496 \\
\hline 88 & $\mathrm{C}_{4} \mathrm{H}_{6}$ (cyclobutene) & 37.40 & -24.075 & 9.631 & -4.062 & -2.388 \\
\hline 89 & $\mathrm{C}_{4} \mathrm{H}_{8}$ (cyclobutane) & 6.80 & -20.801 & 15.535 & 0.805 & 3.359 \\
\hline 90 & $\mathrm{C}_{4} \mathrm{H}_{8}$ (isobutene) & -4.00 & -19.118 & 16.213 & 1.368 & 4.094 \\
\hline 91 & $\mathrm{C}_{4} \mathrm{H}_{10}($ trans butane $)$ & -30.00 & -14.851 & 22.737 & 7.056 & 10.806 \\
\hline 92 & $\mathrm{C}_{4} \mathrm{H}_{10}$ (isobutane) & -32.07 & -13.934 & 24.104 & 8.212 & 11.886 \\
\hline 93 & $\mathrm{C}_{5} \mathrm{H}_{8}$ (spiropentane) & 44.30 & -33.677 & 10.475 & -7.257 & $-\mathbf{5 . 6 3 9}$ \\
\hline 94 & $\mathrm{C}_{6} \mathrm{H}_{6}$ (benzene) & 19.74 & -44.085 & 6.258 & -14.741 & -13.723 \\
\hline 95 & $\mathrm{H}_{2} \mathrm{CF}_{2}$ & -107.71 & -16.299 & 1.510 & -5.574 & -4.691 \\
\hline 96 & $\mathrm{HCF}_{3}$ & -166.60 & -23.537 & -0.192 & -9.266 & -8.800 \\
\hline 97 & $\mathrm{H}_{2} \mathrm{CCl}_{2}$ & -22.83 & -11.713 & 3.453 & -2.348 & -1.915 \\
\hline 98 & $\mathrm{HCCl}_{3}$ & -24.66 & -17.132 & 2.120 & -5.063 & -5.243 \\
\hline 99 & $\mathrm{H}_{3} \mathrm{C}-\mathrm{NH}_{2}$ (methylamine) & -5.50 & -9.959 & 7.066 & -0.368 & 2.192 \\
\hline 100 & $\mathrm{CH}_{3}-\mathrm{CN}$ (methyl cyanide) & 18.00 & -20.581 & 0.117 & -9.052 & -7.820 \\
\hline 101 & $\mathrm{CH}_{3}-\mathrm{NO}_{2}$ (nitromethane) & -17.80 & -42.268 & -12.908 & -25.078 & -23.417 \\
\hline 102 & $\mathrm{CH}_{3}-\mathrm{O}-\mathrm{N}=\mathrm{O}$ (methyl nitrite) & -15.90 & -39.770 & -10.840 & -23.020 & -21.082 \\
\hline 103 & $\mathrm{CH}_{3}-\mathrm{SiH}_{3}$ (methyl silane) & -7.00 & 4.497 & 18.414 & 12.530 & 15.508 \\
\hline 104 & $\mathrm{HCOOH}$ (formic acid) & -90.50 & -23.343 & -2.306 & -10.846 & -9.772 \\
\hline 105 & $\mathrm{HCOOCH}_{3}$ (methyl formate) & -85.00 & -29.267 & 1.516 & -11.206 & -9.383 \\
\hline 106 & $\mathrm{CH}_{3} \mathrm{CONH}_{2}$ (acetamide) & -57.00 & -29.514 & 3.039 & -10.777 & -8.473 \\
\hline 107 & $\mathrm{CH}_{2}-\mathrm{NH}-\mathrm{CH}_{2}$ (aziridine) & 30.20 & -21.528 & 3.303 & -7.046 & -5.058 \\
\hline 108 & NCCN (cyanogen) & 73.30 & -36.243 & -12.904 & -23.829 & -23.733 \\
\hline 109 & $\left(\mathrm{CH}_{3}\right)_{2} \mathrm{NH}$ (dimethylamine) & -4.40 & -15.036 & 11.947 & 0.340 & 3.601 \\
\hline 110 & $\mathrm{CH}_{3}-\mathrm{CH}_{2}-\mathrm{NH}_{2}$ (trans ethylamine) & -11.30 & -15.600 & 11.421 & -0.186 & 3.027 \\
\hline 111 & $\mathrm{H}_{2} \mathrm{C}=\mathrm{C}=\mathrm{O}$ (ketene) & -11.35 & -27.334 & -7.114 & -15.515 & -14.955 \\
\hline 112 & $\mathrm{H}_{2} \mathrm{C}-\mathrm{O}-\mathrm{CH}_{2}$ (oxirane) & -12.57 & -21.168 & 2.008 & -7.277 & -5.847 \\
\hline 113 & $\mathrm{CH}_{3} \mathrm{CHO}$ (acetaldehyde) & -39.70 & -19.248 & 3.162 & -6.161 & -4.597 \\
\hline 114 & $\mathrm{O}=\mathrm{CH}-\mathrm{CH}=\mathrm{O}($ glyoxal $)$ & -50.70 & -31.633 & -4.935 & -16.055 & -15.295 \\
\hline 115 & $\mathrm{CH}_{3}-\mathrm{CH}_{2} \mathrm{OH}$ (ethanol) & -56.21 & -13.216 & 12.485 & 1.847 & 4.454 \\
\hline 116 & $\mathrm{CH}_{3}-\mathrm{O}-\mathrm{CH}_{3}$ (dimethylether) & -44.00 & -14.305 & 11.186 & 0.547 & 3.231 \\
\hline 117 & $\mathrm{CH}_{2}-\mathrm{S}-\mathrm{CH}_{2}$ (thiooxirane) & 19.60 & -17.041 & 4.350 & -3.978 & -2.979 \\
\hline 118 & $\mathrm{CH}_{3} \mathrm{CH}_{3} \mathrm{SO}$ (dimethyl sulfoxide) & -36.20 & -19.784 & 11.471 & -1.217 & 1.151 \\
\hline 119 & $\mathrm{CH}_{3}-\mathrm{CH}_{2}-\mathrm{SH}$ (ethanethiol) & -11.10 & -9.332 & 13.942 & 4.568 & 6.830 \\
\hline 120 & $\mathrm{CH}_{3}-\mathrm{S}-\mathrm{CH}_{3}$ (dimethyl sulphide) & -8.90 & -10.640 & 12.347 & 3.068 & 5.331 \\
\hline 121 & $\mathrm{H}_{2} \mathrm{C}=\mathrm{CHF}$ & -33.20 & -19.563 & 0.776 & -7.655 & -6.661 \\
\hline 122 & $\mathrm{CH}_{3}-\mathrm{CH}_{2}-\mathrm{Cl}$ (ethyl chloride) & -26.80 & -10.966 & 10.457 & 1.769 & 3.514 \\
\hline 123 & $\mathrm{H}_{2} \mathrm{C}=\mathrm{CHCl}$ (vinyl chloride) & 8.90 & -19.513 & -0.568 & -8.305 & -7.554 \\
\hline 124 & $\mathrm{H}_{2} \mathrm{C}=\mathrm{CHCN}$ (acrylonitrile) & 43.20 & -27.966 & -0.104 & -12.427 & -11.471 \\
\hline 125 & $\mathrm{CH}_{3}-\mathrm{CO}-\mathrm{CH}_{3}$ (acetone) & -51.93 & -24.095 & 8.474 & -5.070 & -2.863 \\
\hline 126 & $\mathrm{CH}_{3} \mathrm{COOH}$ (acetic acid) & -103.40 & -27.793 & 3.287 & -9.416 & -7.708 \\
\hline 127 & $\mathrm{CH}_{3} \mathrm{COF}$ (acetyl fluoride) & -105.70 & -27.814 & 0.008 & -11.306 & -10.225 \\
\hline 128 & $\mathrm{CH}_{3} \mathrm{COCl}$ (acetyl chloride) & -58.00 & -27.286 & -0.934 & -11.544 & -10.630 \\
\hline 129 & $\mathrm{CH}_{3} \mathrm{CH}_{2} \mathrm{CH}_{2} \mathrm{Cl}$ (propyl chloride) & -31.52 & -15.542 & 15.762 & 2.957 & 5.366 \\
\hline 130 & $\left(\mathrm{CH}_{3}\right)_{2} \mathrm{CH}-\mathrm{OH}$ (isopropanol) & -65.20 & -17.310 & 18.780 & 3.796 & 7.008 \\
\hline
\end{tabular}


TABLE VII. (Continued.)

\begin{tabular}{|c|c|c|c|c|c|c|}
\hline No. & Molecule & Expt. & PBE & revPBE & B86PBE & xPBE \\
\hline 131 & $\mathrm{C}_{2} \mathrm{H}_{5}-\mathrm{O}-\mathrm{CH}_{3}$ (methyl ethyl ether) & -51.70 & -19.170 & 16.297 & 1.505 & 4.822 \\
\hline 132 & $\left(\mathrm{CH}_{3}\right)_{3} \mathrm{~N}$ (trimethylamine) & -5.70 & -19.884 & 17.640 & 1.573 & 5.534 \\
\hline 133 & $\mathrm{C}_{4} \mathrm{H}_{4} \mathrm{O}$ (furan) & -8.30 & -39.871 & 0.718 & -15.806 & -14.898 \\
\hline 134 & $\mathrm{C}_{4} \mathrm{H}_{4} \mathrm{~S}$ (thiophene) & 27.50 & -34.987 & 3.260 & -12.047 & -11.618 \\
\hline 135 & $\mathrm{C}_{4} \mathrm{H}_{4} \mathrm{NH}$ (pyrrole) & 25.90 & -41.303 & 1.151 & -16.543 & -15.115 \\
\hline 136 & $\mathrm{C}_{5} \mathrm{H}_{5} \mathrm{~N}$ (pyridine) & 33.60 & -49.860 & -0.806 & -21.587 & -20.339 \\
\hline 137 & $\mathrm{SH}$ & 34.18 & -1.147 & 0.800 & 0.114 & 0.631 \\
\hline 138 & $\mathrm{CCH}$ & 135.10 & -10.080 & 0.537 & -4.094 & -4.248 \\
\hline 139 & $\mathrm{C}_{2} \mathrm{H}_{3}\left({ }^{2} A^{\prime}\right)$ & 71.60 & -13.700 & -0.289 & -6.077 & -5.140 \\
\hline 140 & $\mathrm{CH}_{3} \mathrm{CO}\left({ }^{2} A^{\prime}\right)$ & -2.40 & -23.816 & -3.220 & -11.809 & -10.694 \\
\hline 141 & $\mathrm{H}_{2} \mathrm{COH}\left({ }^{2} A\right)$ & -4.08 & -13.259 & 0.800 & -5.012 & -3.541 \\
\hline 142 & $\mathrm{CH}_{3} \mathrm{O}\left({ }^{2} A^{\prime}\right)$ & 4.10 & -12.861 & 0.068 & -5.394 & -4.024 \\
\hline 143 & $\mathrm{CH}_{3} \mathrm{CH}_{2} \mathrm{O}\left({ }^{2} A^{\prime \prime}\right)$ & -3.70 & -14.278 & 8.585 & -1.032 & 0.992 \\
\hline 144 & $\mathrm{CH}_{3} \mathrm{~S}\left({ }^{2} A^{\prime}\right)$ & 29.80 & -8.674 & 2.733 & -1.897 & -0.718 \\
\hline 145 & $\mathrm{C}_{2} \mathrm{H}_{5}\left({ }^{2} A^{\prime}\right)$ & 28.90 & -9.749 & 5.909 & -0.701 & 1.217 \\
\hline 146 & $\left(\mathrm{CH}_{3}\right)_{2} \mathrm{CH}\left({ }^{2} A^{\prime}\right)$ & 21.50 & -15.629 & 9.997 & -0.730 & 1.832 \\
\hline 147 & $\left(\mathrm{CH}_{3}\right)_{3} \mathrm{C}$ & 12.30 & -19.811 & 16.060 & 1.074 & 4.346 \\
\hline 148 & $\mathrm{NO}_{2}$ & 7.91 & -42.513 & -25.374 & -32.455 & -32.021 \\
\hline MAD & & $\cdots$ & 16.9 & 7.3 & 7.9 & 8.0 \\
\hline
\end{tabular}

leading to MAD $8.6 \mathrm{kcal} / \mathrm{mol}$, with a maximum error of $-25 \mathrm{kcal} / \mathrm{mol}$ at nitromethane.

For the subset of radicals (No. 138-148 in Table VII), $\mathrm{PBE}$ leads to $\mathrm{MAD}=16.8 \mathrm{kcal} / \mathrm{mol}$, with a maximum error of $-42.5 \mathrm{kcal} / \mathrm{mol}$ at $\mathrm{NO}_{2}$. Errors for the other three functionals are significantly smaller, with $\mathrm{MAD}=6.7$ (revPBE), 6.4 (B86PBE), and 6.3 (xPBE). All these functionals have problems for $\mathrm{NO}_{2}$, leading to errors of -25.4 (revPBE), -32.5 (B86PBE), and -32.0 (xPBE).

The fluorine- and chlorine-containing compounds of the $G 2$ set are generally most difficult to describe well. This subset of compounds (No. 57-77 in Table VII) leads to MADs of $23.7 \mathrm{kcal} / \mathrm{mol}$ (PBE), 11.9 (revPBE), 15.1 (B86PBE), and $15.2 \mathrm{kcal} / \mathrm{mol}$ (xPBE). The largest errors encountered are $-50.5\left(\mathrm{C}_{2} \mathrm{~F}_{4}, \mathrm{PBE}\right), 29.7\left(\mathrm{SiF}_{4}\right.$, revPBE), $-29.4\left(\mathrm{~N}_{2} \mathrm{O}, \mathrm{B} 86 \mathrm{PBE}\right)$, and $-29.1 \mathrm{kcal} / \mathrm{mol}\left(\mathrm{C}_{2} \mathrm{~F}_{4}, \mathrm{xPBE}\right)$.

We should point out that although the modified versions of PBE generally improve the accuracy for the thermochemistry, there are cases where the results get considerably worse. For example, PBE overbinds $\mathrm{SiCl}_{4}$ by $3.2 \mathrm{kcal} / \mathrm{mol}$, while it is underbound by 16.3 (revPBE) and 9.2 (B86PBE, $\mathrm{xPBE})$. Perdew et al. have criticized that revPBE improves the energetics of multiple bonds by worsening many single bonds. ${ }^{46}$ This tendency is seen clearly in the data of Table VII.

\section{Ionization potentials, electron affinities, and proton affinities}

Table VIII lists the experimental ionization potentials (IPs) and the theoretical deviations from experiments for the 18 atoms and 24 molecules in the $G 2$ set; ${ }^{27,29}$ while Table IX lists the results of electron affinities (EA) for the 7 atoms and 18 molecules in the $G 2$ set. $^{27,29}$ We calculated IP and EA as energy differences between the neutral species and the corresponding ionic species. Very accurate experimental IPs for atoms are known providing a good test of the ability of the functionals to handle positively charged systems. For the atomic systems, the MADs are $0.159 \mathrm{eV}$ (PBE), 0.136 (revPBE), 0.159 (B86PBE), and 0.149 (xPBE). For the molecular systems, the MADs are $0.153 \mathrm{eV}$ (PBE), 0.189 (revPBE), 0.156 (B86PBE), and 0.180 (xPBE). The MADs for the total 42 systems are 0.156 (PBE), 0.166 (revPBE), 0.158 (B86PBE), and 0.167 (xPBE). The IP of $\mathrm{O}$ is a problem for all four functionals. PW91 leads to $\mathrm{MAD}=0.164,{ }^{46}$ while BLYP leads to MAD $=0.187 \mathrm{kcal} / \mathrm{mol}$ (Refs. 29 and 46) for the same set.

There has been some debate in the literature, concerning whether DFT methods are suitable for calculating electron affinities. ${ }^{47-50}$ On one hand, the "self-interaction error" causes the Kohn-Sham orbital energies to be shifted upwards artificially, leading to positive (unstable) orbital energies for the highest occupied orbitals of an anion. On the other hand, an artificial stabilization is provided by employing a finite basis sets with functions localized at the anion.

Actual numerical calculations demonstrate that DFT methods predict electron affinities with an accuracy comparable to conventional $a b$ initio calculations. ${ }^{30,50}$ For the atomic systems, the MAD are $0.130 \mathrm{eV}$ (PBE), 0.071 (revPBE), 0.119 (B86PBE), and 0.081 (xPBE). All four functionals perform significantly better for the second low atoms.

For the molecular systems, the MAD are $0.090 \mathrm{eV}$ (PBE), 0.098 (revPBE), 0.091 (B86PBE), and 0.093 (xPBE). The EA of $\mathrm{C}$ and $\mathrm{CH}$ are problematic for PBE, while EA of $\mathrm{Cl}_{2}$ is problematic for revPBE, B86PBE, and xPBE. The MAD for the total 25 systems are 0.101 (PBE), 0.091 (revPBE), 0.099 (B86PBE), and 0.091 (xPBE) eV. For PW91 and BLYP, similar calculations lead to 0.141 (PW91) and 0.106 (BLYP). ${ }^{29,46}$

Table $\mathrm{X}$ lists the proton affinities PAs at $0 \mathrm{~K}$ for the eight cases in the $G 2$ set and the MAD (theory-expt) obtained from $\mathrm{PBE}$, revPBE, B86PBE, and XPBE. PBE leads to MAD $=1.45 \mathrm{kcal} / \mathrm{mol}$ with maximum negative deviation being $-3.98 \mathrm{kcal} / \mathrm{mol}$. PAs are always underestimated in PBE as shown by the lack of any positive deviations with this func- 
TABLE VIII. Ionization potentials (in eV) at $0 \mathrm{~K}$ of the 42 systems in $G 2$ (Refs. 7 and 29) and the deviations (theory-expt) obtained from PBE, revPBE, B86PBE, and xPBE using aug-cc-pVTZ basis sets. $G 2$ geometries (Refs. 27 and 28) are used in the DFT calculations. The best DFT results are in boldface.

\begin{tabular}{|c|c|c|c|c|c|c|}
\hline No. & System & Expt. & PBE & revPBE & B86PBE & xPBE \\
\hline 1 & $\mathrm{H} \rightarrow \mathrm{H}^{+}$ & 13.60 & 0.00 & 0.12 & 0.10 & 0.08 \\
\hline 2 & $\mathrm{He} \rightarrow \mathrm{He}^{+}$ & 24.59 & -0.14 & 0.02 & 0.01 & -0.03 \\
\hline 3 & $\mathrm{Li} \rightarrow \mathrm{Li}^{+}$ & 5.39 & 0.18 & 0.20 & 0.22 & 0.19 \\
\hline 4 & $\mathrm{Be} \rightarrow \mathrm{Be}^{+}$ & 9.32 & -0.32 & -0.30 & -0.27 & -0.33 \\
\hline 5 & $\mathrm{~B} \rightarrow \mathrm{B}^{+}$ & 8.30 & 0.37 & 0.34 & 0.39 & 0.36 \\
\hline 6 & $\mathrm{C} \rightarrow \mathrm{C}^{+}$ & 11.26 & 0.28 & 0.22 & 0.28 & 0.25 \\
\hline 7 & $\mathrm{~N} \rightarrow \mathrm{N}^{+}$ & 14.54 & 0.20 & 0.12 & 0.18 & 0.15 \\
\hline 8 & $\mathrm{O} \rightarrow \mathrm{O}^{+}$ & 13.61 & 0.46 & 0.38 & 0.50 & 0.44 \\
\hline 9 & $\mathrm{~F} \rightarrow \mathrm{F}^{+}$ & 17.42 & 0.26 & 0.14 & 0.25 & 0.21 \\
\hline 10 & $\mathrm{Ne} \rightarrow \mathrm{Ne}^{+}$ & 21.56 & 0.15 & 0.01 & 0.11 & 0.08 \\
\hline 11 & $\mathrm{CH}_{4} \rightarrow \mathrm{CH}_{4}^{+}$ & 12.62 & -0.24 & -0.28 & -0.22 & -0.27 \\
\hline 12 & $\mathrm{NH}_{3} \rightarrow \mathrm{NH}_{3}^{+}$ & 10.18 & -0.01 & -0.08 & -0.02 & -0.07 \\
\hline 13 & $\mathrm{OH} \rightarrow \mathrm{OH}^{+}$ & 13.01 & 0.16 & 0.07 & 0.16 & 0.11 \\
\hline 14 & $\mathrm{H}_{2} \mathrm{O} \rightarrow \mathrm{H}_{2} \mathrm{O}^{+}$ & 12.62 & -0.03 & -0.12 & -0.04 & -0.09 \\
\hline 15 & $\mathrm{HF} \rightarrow \mathrm{HF}^{+}$ & 16.04 & 0.03 & -0.08 & 0.00 & -0.04 \\
\hline 16 & $\mathrm{Na} \rightarrow \mathrm{Na}^{+}$ & 5.14 & 0.21 & 0.16 & 0.22 & 0.20 \\
\hline 17 & $\mathrm{Mg} \rightarrow \mathrm{Mg}^{+}$ & 7.65 & -0.03 & -0.09 & -0.02 & -0.08 \\
\hline 18 & $\mathrm{Al} \rightarrow \mathrm{Al}^{+}$ & 5.98 & 0.09 & 0.10 & 0.11 & 0.07 \\
\hline 19 & $\mathrm{Si} \rightarrow \mathrm{Si}^{+}$ & 8.15 & 0.05 & 0.03 & 0.06 & 0.02 \\
\hline 20 & $\mathrm{P} \rightarrow \mathrm{P}^{+}$ & 10.49 & 0.00 & -0.03 & 0.00 & -0.04 \\
\hline 21 & $\mathrm{~S} \rightarrow \mathrm{S}^{+}$ & 10.36 & 0.07 & 0.04 & 0.09 & $\mathbf{0 . 0 3}$ \\
\hline 22 & $\mathrm{Cl} \rightarrow \mathrm{Cl}^{+}$ & 12.97 & 0.01 & -0.05 & 0.01 & -0.04 \\
\hline 23 & $\mathrm{Ar} \rightarrow \mathrm{Ar}^{+}$ & 15.76 & -0.04 & -0.10 & -0.05 & -0.09 \\
\hline 24 & $\mathrm{SiH}_{4} \rightarrow \mathrm{SiH}_{4}^{+}$ & 11.00 & -0.30 & -0.35 & -0.29 & -0.35 \\
\hline 25 & $\mathrm{PH} \rightarrow \mathrm{PH}^{+}$ & 10.15 & 0.10 & 0.08 & 0.11 & 0.06 \\
\hline 26 & $\mathrm{PH}_{2} \rightarrow \mathrm{PH}_{2}^{+}$ & 9.82 & 0.17 & 0.14 & 0.18 & 0.13 \\
\hline 27 & $\mathrm{PH}_{3} \rightarrow \mathrm{PH}_{3}^{+}$ & 9.87 & -0.08 & -0.14 & -0.08 & -0.13 \\
\hline 28 & $\mathrm{SH} \rightarrow \mathrm{SH}^{+}$ & 10.37 & 0.01 & -0.03 & 0.02 & -0.04 \\
\hline 29 & $\mathrm{H}_{2} \mathrm{~S} \rightarrow \mathrm{H}_{2} \mathrm{~S}^{+}\left({ }^{2} B_{1}\right)$ & 10.47 & -0.10 & -0.15 & -0.10 & -0.15 \\
\hline 30 & $\mathrm{H}_{2} \mathrm{~S} \rightarrow \mathrm{H}_{2} \mathrm{~S}^{+}\left({ }^{2} A_{1}\right)$ & 12.78 & -0.22 & -0.26 & -0.21 & -0.26 \\
\hline 31 & $\mathrm{HCl} \rightarrow \mathrm{HCl}^{+}$ & 12.75 & -0.06 & -0.12 & -0.07 & -0.12 \\
\hline 32 & $\mathrm{C}_{2} \mathrm{H}_{2} \rightarrow \mathrm{C}_{2} \mathrm{H}_{2}^{+}$ & 11.40 & -0.16 & -0.27 & -0.19 & -0.23 \\
\hline 33 & $\mathrm{C}_{2} \mathrm{H}_{4} \rightarrow \mathrm{C}_{2} \mathrm{H}_{4}^{+}$ & 10.51 & -0.10 & -0.21 & -0.13 & -0.18 \\
\hline 34 & $\mathrm{CO} \rightarrow \mathrm{CO}^{+}$ & 14.01 & -0.14 & -0.20 & -0.13 & -0.19 \\
\hline 35 & $\mathrm{~N}_{2} \rightarrow \mathrm{N}_{2}^{+}\left({ }^{2} \Sigma_{g}\right)$ & 15.58 & -0.18 & -0.27 & -0.19 & -0.24 \\
\hline 36 & $\mathrm{~N}_{2} \rightarrow \mathrm{N}_{2}^{+}\left({ }^{2} \Pi_{u}\right)$ & 16.70 & -0.13 & -0.28 & 0.18 & -0.22 \\
\hline 37 & $\mathrm{O}_{2} \rightarrow \mathrm{O}_{2}^{+}$ & 12.07 & 0.40 & 0.33 & 0.40 & 0.36 \\
\hline 38 & $\mathrm{P}_{2} \rightarrow \mathrm{P}_{2}^{+}$ & 10.53 & 0.26 & 0.21 & 0.26 & 0.21 \\
\hline 39 & $\mathrm{~S}_{2} \rightarrow \mathrm{S}_{2}^{+}$ & 9.36 & 0.10 & 0.09 & 0.12 & 0.07 \\
\hline 40 & $\mathrm{Cl}_{2} \rightarrow \mathrm{Cl}_{2}^{+}$ & 11.50 & -0.35 & -0.38 & -0.34 & -0.39 \\
\hline 41 & $\mathrm{ClF} \rightarrow \mathrm{ClF}^{+}$ & 12.66 & -0.30 & -0.34 & -0.29 & -0.33 \\
\hline \multirow[t]{2}{*}{42} & $\mathrm{CS} \rightarrow \mathrm{CS}^{+}$ & 11.33 & -0.03 & -0.06 & -0.01 & -0.08 \\
\hline & MAD & $\ldots$ & 0.156 & 0.166 & 0.158 & 0.167 \\
\hline
\end{tabular}

tional. The MAD for these eight systems are 1.19 (revPBE), 1.08 (B86PBE), and $1.07 \mathrm{kcal} / \mathrm{mol}$ (xPBE). For comparison, the MAD $=1.43$ for PW91 and 1.96 for BLYP. ${ }^{29,46}$

\section{E. Bonding properties of rare-gas dimers}

Rare-gas dimers are the least ambiguous test molecules for London dispersion or van der Waals attraction interactions. Table XI summarizes the bonding properties of $\mathrm{He}_{2}$, $\mathrm{Ne}_{2}$, and $\mathrm{Ar}_{2}$ calculated with different flavors of DFT functionals. Although the B88 exchange functional is very successful for describing covalent bonds, it fails to describe van der Waals interactions. ${ }^{46,51,52}$ Thus every DFT method using the B88 exchange functional (pure or hybrid) gives unbounded rare-gas dimers; while every DFT method using the PW91 exchange functional severely overbinds the $\mathrm{He}_{2}$ and
$\mathrm{Ne}_{2}$ rare-gas dimers. ${ }^{46}$ Adamo and Barone modified PW91 (Ref. 21) by fitting the differential exchange energies of raregas dimers to HF values, thus removing most of the overbinding tendency of PW91. Their mPWPW model yields $R(\mathrm{He}-\mathrm{He})=3.14 \AA$ and $\Delta E(\mathrm{He}-\mathrm{He})=0.069 \mathrm{kcal} / \mathrm{mol},{ }^{21}$ as compared to the PW91 values of $R(\mathrm{He}-\mathrm{He})=2.645 \AA$ and $\Delta E(\mathrm{He}-\mathrm{He})=0.231 \mathrm{kcal} / \mathrm{mol}$ (Ref. 21) and the experimental data of $R(\mathrm{He}-\mathrm{He})=2.970 \AA \Delta E(\mathrm{He}-\mathrm{He})=0.022 \mathrm{kcal} / \mathrm{mol} .{ }^{43}$

The PBE functional gives a better description of rare-gas dimers than PW91 or BLYP. ${ }^{46,53,54}$ For $\mathrm{Ne}_{2}$, PBE yields $R$ $=3.097 \AA$ and $\Delta E=0.111 \mathrm{kcal} / \mathrm{mol}$, which compares well with the experimental data of $R(\mathrm{Ne}-\mathrm{Ne})$ $=3.091 \AA, \Delta E(\mathrm{Ne}-\mathrm{Ne})=0.084 \mathrm{kcal} / \mathrm{mol} .{ }^{43}$ But $\mathrm{PBE}$ still overestimates $\Delta E(\mathrm{He}-\mathrm{He})$ by $236 \%$ and underestimates $\Delta E(\mathrm{Ar}-\mathrm{Ar})$ by $56 \%$. The revPBE functional gives satisfac- 
TABLE IX. Electron affinities (in eV) at $0 \mathrm{~K}$ of 25 systems of $G 2$ (Refs. 7 and 29) and the deviations (theory-expt.) obtained from PBE, revPBE, B86PBE, and xPBE using aug-cc-pVTZ basis set. $G 2$ geometries (Refs. 27 and 28) are used in the DFT calculations. The best DFT results are in boldface.

\begin{tabular}{llrrrrr}
\hline \hline No. & System & Expt. & PBE & revPBE & B86PBE & xPBE \\
\hline 1 & $\mathrm{C} \leftarrow \mathrm{C}^{-}$ & 1.26 & 0.29 & $\mathbf{0 . 2 3}$ & 0.27 & 0.24 \\
2 & $\mathrm{CH} \leftarrow \mathrm{CH}^{-}$ & 1.24 & 0.29 & $\mathbf{0 . 2 2}$ & 0.27 & 0.23 \\
3 & ${ }^{3} \mathrm{CH}_{2} \leftarrow \mathrm{CH}_{2}^{-}$ & 0.65 & 0.11 & 0.06 & 0.12 & $\mathbf{0 . 0 5}$ \\
4 & $\mathrm{CH}_{3} \leftarrow \mathrm{CH}_{3}^{-}$ & 0.08 & $\mathbf{0 . 0 0}$ & -0.07 & -0.02 & -0.07 \\
5 & $\mathrm{NH} \leftarrow \mathrm{NH}^{-}$ & 0.38 & 0.10 & $\mathbf{0 . 0 2}$ & 0.10 & 0.04 \\
6 & $\mathrm{NH}_{2} \leftarrow \mathrm{NH}_{2}^{-}$ & 0.74 & 0.03 & -0.06 & $\mathbf{0 . 0 1}$ & -0.05 \\
7 & $\mathrm{O} \leftarrow \mathrm{O}^{-}$ & 1.46 & 0.20 & $\mathbf{0 . 1 0}$ & 0.19 & 0.14 \\
8 & $\mathrm{OH} \leftarrow \mathrm{OH}^{-}$ & 1.83 & 0.02 & -0.08 & $\mathbf{0 . 0 0}$ & -0.05 \\
9 & $\mathrm{~F} \leftarrow \mathrm{F}^{-}$ & 3.40 & 0.15 & $\mathbf{0 . 0 2}$ & 0.11 & 0.07 \\
10 & $\mathrm{O} \leftarrow \mathrm{O}_{2}^{-}$ & 0.44 & -0.04 & -0.10 & $-\mathbf{0 . 0 2}$ & -0.07 \\
11 & $\mathrm{NO} \leftarrow \mathrm{NO}^{-}$ & 0.02 & 0.24 & $\mathbf{0 . 2 1}$ & 0.26 & $\mathbf{0 . 2 1}$ \\
12 & $\mathrm{CN} \leftarrow \mathrm{CN}^{-}$ & 3.82 & -0.01 & -0.06 & $\mathbf{0 . 0 0}$ & -0.06 \\
13 & $\mathrm{Si} \leftarrow \mathrm{Si}^{-}$ & 1.38 & 0.08 & 0.05 & 0.08 & $\mathbf{0 . 0 4}$ \\
14 & $\mathrm{P} \leftarrow \mathrm{P}^{-}$ & 0.75 & 0.10 & 0.06 & 0.11 & $\mathbf{0 . 0 4}$ \\
15 & $\mathrm{~S} \leftarrow \mathrm{S}^{-}$ & 2.08 & 0.06 & $\mathbf{0 . 0 0}$ & 0.06 & $\mathbf{0 . 0 0}$ \\
16 & $\mathrm{Cl} \leftarrow \mathrm{Cl}^{-}$ & 3.62 & 0.03 & -0.04 & $\mathbf{0 . 0 1}$ & -0.04 \\
17 & $\mathrm{SiH} \leftarrow \mathrm{SiH}^{-}$ & 1.28 & 0.10 & 0.06 & 0.09 & $\mathbf{0 . 0 5}$ \\
18 & ${ }^{1} \mathrm{SiH}_{2} \leftarrow \mathrm{SiH}_{2}^{-}$ & 1.12 & 0.15 & 0.12 & 0.15 & $\mathbf{0 . 1 1}$ \\
19 & $\mathrm{SiH} \leftarrow \mathrm{SiH}_{3}^{-}$ & 1.44 & $-\mathbf{0 . 0 3}$ & -0.09 & -0.04 & -0.09 \\
20 & $\mathrm{PH} \leftarrow \mathrm{PH}^{-}$ & 1.00 & 0.05 & $-\mathbf{0 . 0 1}$ & 0.04 & $-\mathbf{0 . 0 1}$ \\
21 & $\mathrm{PH} \leftarrow \mathrm{PH}_{2}^{-}$ & 1.26 & $-\mathbf{0 . 0 1}$ & -0.08 & -0.03 & -0.08 \\
22 & $\mathrm{SH} \leftarrow \mathrm{SH}^{-}$ & 2.31 & $\mathbf{0 . 0 1}$ & -0.06 & $-\mathbf{0 . 0 1}$ & -0.06 \\
23 & $\mathrm{PO} \leftarrow \mathrm{PO}^{-}$ & 1.09 & 0.09 & $\mathbf{0 . 0 7}$ & 0.10 & 0.06 \\
24 & $\mathrm{~S} \leftarrow \mathrm{S}_{2}^{-}$ & 1.66 & -0.10 & -0.13 & $\mathbf{- 0 . 0 8}$ & $-\mathbf{0 . 1 4}$ \\
25 & $\mathrm{Cl} \mathrm{Cl}_{2}^{-}$ & 2.39 & 0.24 & 0.26 & 0.30 & 0.25 \\
& $\mathrm{MAD}$ & $\ldots$ & 0.101 & $\mathbf{0 . 0 9 1}$ & 0.099 & $\mathbf{0 . 0 9 1}$ \\
\hline \hline & & & & & &
\end{tabular}

tory results for $\mathrm{He}_{2}$, but significantly underbinds $\mathrm{Ne}_{2}$ and $\mathrm{Ar}_{2}$. B86PBE and $\mathrm{xPBE}$ reduce the overbinding tendency of $\mathrm{PBE}$ for $\mathrm{He}_{2}$ and $\mathrm{Ne}_{2}$ and give the best description of $\mathrm{Ne}_{2}$.

Based on these results we expect that XPBE should lead to a good description of the London forces between electron pairs involving the first ten atoms of the periodic table, making it useful for the most common organic and biological systems.

It is well known that the long-range correlation is absent in the conventional density functionals. ${ }^{54-57}$ Fundamental improvement on the functional is needed to describe correctly the physics of the long-range London-dispersion interactions. ${ }^{58,59}$

\section{F. Bonding properties of water dimer}

Hydrogen bonding plays a critical role in a wide range of chemical and biological phenomena. Thus water dimer, the prototypical hydrogen bonded system, has received much experimental and theoretical attention. ${ }^{60-68}$ One difficulty in assessing the accuracy in the DFT methods is that the experimental determinations of $R_{e}$ and $D_{e}$ have been unreliable due to the floppy nature of the dimer. Microwave measurements lead to a vibrationally averaged O...O distance of $R_{0}$ $=2.976 \AA$, from which it was estimated that $R_{e}=2.952 \AA{ }^{64}$ The widely accepted experimental $D_{e}$ of $5.44 \pm 0.7 \mathrm{kcal} / \mathrm{mol}$ (Ref. 68) is indirect, being based on the interpretation of

TABLE X. Proton affinities (in $\mathrm{kcal} / \mathrm{mol}$ ) at $0 \mathrm{~K}$ for the eight systems of $G 2$ (Refs. 7 and 29) and the deviations (theory-expt.) obtained from PBE, revPBE, B86PBE, and xPBE using aug-cc-pVTZ. G2 geometries (Refs. 27 and 28) are used in the DFT calculations. The best DFT results are in boldface.

\begin{tabular}{llccrrr}
\hline \hline No. & System & Expt. & PBE & revPBE & B86PBE & xPBE \\
\hline 1 & $\mathrm{H}_{2} \leftarrow \mathrm{H}_{3}^{+}$ & 100.8 & -1.23 & $-\mathbf{0 . 1 5}$ & -0.74 & -0.75 \\
2 & $\mathrm{NH}_{3} \leftarrow \mathrm{NH}_{4}^{+}$ & 202.5 & -1.02 & 0.52 & $-\mathbf{0 . 2 0}$ & -0.22 \\
3 & $\mathrm{H}_{2} \mathrm{O} \leftarrow \mathrm{H}_{3} \mathrm{O}^{+}$ & 165.1 & -2.42 & $-\mathbf{1 . 2 8}$ & -1.90 & 1.99 \\
4 & $\mathrm{C}_{2} \mathrm{H}_{2} \leftarrow \mathrm{C}_{2} \mathrm{H}_{3}^{+}$ & 152.3 & $-\mathbf{0 . 2 5}$ & 2.52 & 1.38 & 1.24 \\
5 & $\mathrm{SiH}_{4} \leftarrow \mathrm{SiH}_{5}^{+}$ & 154.0 & -1.06 & 1.43 & $\mathbf{0 . 5 3}$ & $\mathbf{0 . 5 3}$ \\
6 & $\mathrm{PH}_{3} \leftarrow \mathrm{PH}_{4}^{+}$ & 187.1 & -3.98 & $-\mathbf{1 . 7 0}$ & -2.51 & 2.53 \\
7 & $\mathrm{H}_{2} \mathrm{~S} \leftarrow \mathrm{H}_{3} \mathrm{~S}^{+}$ & 168.8 & -1.61 & $\mathbf{0 . 2 3}$ & -0.46 & -0.42 \\
8 & $\mathrm{HCl} \leftarrow \mathrm{H}_{2} \mathrm{Cl}^{+}$ & 133.6 & $\mathbf{- 0 . 0 2}$ & 1.69 & 0.90 & 0.90 \\
& $\mathrm{MAD}$ & $\ldots$ & 1.450 & 1.190 & 1.077 & $\mathbf{1 . 0 7 4}$ \\
\hline \hline
\end{tabular}


TABLE XI. Bonding properties of $\mathrm{He}_{2}, \mathrm{Ne}_{2}$, and $\mathrm{Ar}_{2}$ calculated by PBE, revPBE, B86PBE, and xPBE using the aug-cc-pVTZ $(-f)$ basis set. Bond energies are corrected for basis set superposition error (BSSE) effects. Bond lengths are in $\AA$ and bond energies are in $\mathrm{kcal} / \mathrm{mol}$. The best DFT results are in boldface.

\begin{tabular}{lcccccc}
\hline \hline & $R(\mathrm{He}-\mathrm{He})$ & $\Delta E(\mathrm{He}-\mathrm{He})$ & $R(\mathrm{Ne}-\mathrm{Ne})$ & $\Delta E(\mathrm{Ne}-\mathrm{Ne})$ & $R(\mathrm{Ar}-\mathrm{Ar})$ & $\Delta E(\mathrm{Ar}-\mathrm{Ar})$ \\
\hline PBE & 2.752 & 0.074 & $\mathbf{3 . 0 9 7}$ & 0.111 & $\mathbf{4 . 0 0 0}$ & $\mathbf{0 . 1 2 6}$ \\
revPBE & 3.121 & $\mathbf{0 . 0 2 8}$ & 3.454 & 0.049 & 4.695 & 0.031 \\
B86PBE & $\mathbf{2 . 8 6 4}$ & 0.055 & 3.217 & $\mathbf{0 . 0 8 2}$ & 4.266 & 0.075 \\
xPBE & 2.847 & 0.057 & 3.197 & $\mathbf{0 . 0 8 6}$ & 4.250 & 0.078 \\
Expt. $^{\mathrm{a}}$ & 2.970 & 0.022 & 3.091 & 0.084 & 3.757 & 0.285 \\
\hline \hline
\end{tabular}

${ }^{a}$ Reference 44.

measurements of the thermal conductivity of the water vapor. Indeed the most reliable values for the equilibrium geometry and dissociation energy of $\left(\mathrm{H}_{2} \mathrm{O}\right)_{2}$ are from $\mathrm{CCSD}(\mathrm{T})$ (full) coupled cluster calculations using both single and double substitutions from the Hartree-Fock determinant, and including triple excitations noniteratively (with basis sets extrapolated to infinity). This best $a b$ initio calculation leads to $R_{e}(\mathrm{O} \ldots \mathrm{O})=2.912 \pm 0.005 \AA$ and $D_{e}=5.02 \pm 0.10 \mathrm{kcal} / \mathrm{mol} .{ }^{62}$

Table XII lists the calculated bonding properties of $\left(\mathrm{H}_{2} \mathrm{O}\right)_{2}$ from different DFT methods in the PBE family. We see that XPBE leads to $R_{e}$ too long by $0.043 \AA$ with a bond energy too weak by $0.56 \mathrm{kcal} / \mathrm{mol}$. PBE leads to better results, with a bond too short by $0.023 \AA$ and too strong by only $0.09 \mathrm{kcal} / \mathrm{mol}$.

The elongation of the $\mathrm{O}-\mathrm{H}$ bond in the donor water provides a third test of the quality of the description. The best $a b$ initio estimate of $\Delta R_{d}(\mathrm{OH})=0.007 \AA$ is from Bleiber and Sauer ${ }^{63}$ using the fourth-order Møller-Plesset (MP4) method with the $\operatorname{VTZ}(2 d f)$ basis on $\mathrm{O}$ and $\operatorname{VTZ}(2 p)$ on $\mathrm{H}$ PBE leads to $\Delta R_{d}(\mathrm{OH})=0.011 \AA$, a significant overestimate of this quantity, while xPBE leads to $0.009 \AA$.

Another parameter of interest is the frequency shift $\Delta \nu_{d}(\mathrm{OH})$ in the donor $\mathrm{O}-\mathrm{H}$ stretching mode upon forming a hydrogen bond. In calculating this shift we use as the reference $\mathrm{OH}$ mode the arithmetic mean of the symmetric and the asymmetric harmonic stretching modes of the free monomer (since there is a strong coupling of these two modes for $\mathrm{H}_{2} \mathrm{O}$

TABLE XII. Bonding properties of water dimer. The DFT calculations used the aug-cc-pVTZ $(-f)$ basis set. The reference data and the best DFT results are in boldface.

\begin{tabular}{lcccc}
\hline \hline & $R_{e}(\mathrm{O} \ldots \mathrm{O})$ & $\Delta R_{d}(\mathrm{OH})^{\mathrm{a}}$ & $\Delta \nu_{d}(\mathrm{OH})^{\mathrm{b}}$ & $D_{e}$ \\
\hline PBE & $\mathbf{2 . 8 9 9}$ & 0.011 & -217 & $\mathbf{5 . 1 1}$ \\
revPBE & 3.018 & $\mathbf{0 . 0 0 7}$ & $-\mathbf{1 6 4}$ & 3.58 \\
B86PBE & 2.957 & 0.010 & -206 & 4.39 \\
xPBE & 2.955 & 0.009 & -187 & 4.46 \\
Best $a b$ initio & $\mathbf{2 . 9 1 2 \pm 0 . 0 0 5 ^ { \mathrm { c } }}$ & $\mathbf{0 . 0 0 7}^{\mathrm{d}}$ & $-121^{\mathrm{d}}$ & $\mathbf{5 . 0 2} \pm \mathbf{0 . 1 0 ^ { \mathbf { c } }}$ \\
Expt. & $2.952^{\mathrm{e}}$ & $\cdots$ & $\mathbf{- 1 7 0}^{\mathbf{f}}$ & $5.44 \pm 0.7^{\mathrm{g}}$ \\
\hline
\end{tabular}

${ }^{a}$ The enlongation of the $\mathrm{O}-\mathrm{H}$ bond in the donor water.

${ }^{\mathrm{b}}$ The frequency shift of the donor $\mathrm{O}-\mathrm{H}$ stretching mode experienced upon forming a hydrogen bridge.

${ }^{c}$ Reference 62, CCSD(T)(full) IO275 $\rightarrow \infty$ (IO275: interaction optimized basis set with 275 basis functions for $\mathrm{H}_{2} \mathrm{O}$ dimer $\mathrm{O}-7 s 5 p 5 d 3 f 2 g 1 h$; $\left.\mathrm{H}_{d}-2 s 4 p 1 d, \mathrm{H}-2 s 3 p, \mathrm{BF}-3 s 3 p 2 d 1 f\right)$.

${ }^{\mathrm{d}}$ Reference $63, \mathrm{MP} 4 / \mathrm{VTZ}(2 d f)$ on $\mathrm{O}$ and $\operatorname{VTZ}(2 p)$ on $\mathrm{H}$.

${ }^{\mathrm{e}}$ Reference 64.

${ }^{\mathrm{f}}$ References 65-67.

${ }^{g}$ Reference 68 . Experimental $D_{e}$ was estimated by adding the zero-point energy calculated at HF/4-21G level. monomer $\left.{ }^{63}\right)$. The experimental harmonic frequencies of water monomer and dimer lead to $\Delta \nu_{d}(\mathrm{OH})=-170 \mathrm{~cm}^{-1}$. ${ }^{65-67}$ The best $a b$ initio value obtained by Bleiber and Sauer at $\operatorname{MP} 4 / \mathrm{VTZ}(2 d f, 2 p)$ is $-121 \mathrm{~cm}^{-1}, 63$ underestimating the frequency shift by $49 \mathrm{~cm}^{-1}$. The DFT generally performs better with errors in $\Delta \nu_{d}(\mathrm{OH})$ of $47(\mathrm{RBE})$ and $17 \mathrm{~cm}^{-1}$ (xPBE).

As seen from Table XII, it remains a challenge for a pure DFT method to give a good overall description of water dimer. While PBE gives the best predictions on $R_{e}(\mathrm{O} \ldots \mathrm{O})$ and $D_{e}, \mathrm{PBE}$ leads to clear overbinding, with concomitant overestimation of $\Delta R_{d}(\mathrm{OH})$ and $\Delta \nu_{d}(\mathrm{OH})$. On the other hand, revPBE gives the best predictions on $\Delta R_{d}(\mathrm{OH})$ and $\Delta \nu_{d}(\mathrm{OH})$, but revPBE shows clear underbinding with a too long $R_{e}(\mathrm{O} \ldots \mathrm{O})$ and a too small $D_{e}$. Values from xPBE are always close to the best numbers for all four properties, leading us to conclude that XPBE is the most balanced method in the PBE family for the description of hydrogen bonds.

\section{CONCLUDING REMARKS}

Development of improved approximations to the exchange-correlation functional is the key to the continued improvement in the success of Kohn-Sham density functional theory. A variety of exchange-correlation functionals have been developed, each with strengths and limits. We believe that the best strategy for developing improved approximations to the exact exchange-correlation functional within the GGA framework is to combine theory-based physical constraints with fitting a very limited set of parameters to selected experimental data. The physical constraints help to confine the functional forms; but the small gradient/ high density regions and the large gradient/low density regions cannot be uniquely fixed by the physical constraints. But it is important to limit the number of empirical parameters in the functional (by making maximum use of physical concepts) so that systematic improvements of the functional can be achieved.

In line with this approach we started with the wellfounded PBE functional ${ }^{11}$ and extended it by optimizing the $(\mu, \kappa, \alpha, \beta)$ parameters against the experimental atomic data and the van der Waals interaction properties of $\mathrm{Ne}_{2}$. (No other molecular information was used.) This xPBE functional significantly outperforms PBE in the prediction of the atomic data (exchange energies, correlation energies, and total energies for atoms from $\mathrm{H}$ to $\mathrm{Ar}$ ) and the heats of formation (against the extended $G 2$ sets), while maintaining the good performance of PBE for predicting geometry param- 
eters, ionization potentials, electron affinities, and proton affinities (against the extended $G 2$ sets) and for describing van der Waals and hydrogen bond interactions.

Comparing to BLYP, ${ }^{9,16}$ xPBE shows competitive quality in the predictions of the atomic data and the heats of formation of molecular systems. xPBE shows better quality in the predictions of ionization potentials, electron affinities, and proton affinities (against the extended $G 2$ set). In particular, xPBE significantly outperforms BLYP in describing the van der Waals interactions.

As compared to PW91 (GGA II), ${ }^{10,17}$ xPBE corrects, to a great extent, the overbinding tendency in the prediction of the heats of formation against the extended $G 2$ sets, as well as in the description of the van der Waals interactions as represented by $\mathrm{He}_{2}$ and $\mathrm{Ne}_{2}$.

We also present here a detailed systematic validation of two other modified versions of PBE: revPBE (Refs. 11 and 12) and B86PBE. ${ }^{11,16}$ Both functionals significantly improve upon PBE for predicting atomic data and the heats of formation (against the extended $G 2$ set), but revPBE shows a clear tendency for underestimating the van der Waals and hydrogen bond interactions and is poorer than PBE for geometric predictions.

We conclude that XPBE provides a balanced description in covalent bonds as well as the van der Waals and hydrogen bond interactions. Thus xPBE should find applications in a wide range of important chemical and biological systems.

\section{ACKNOWLEDGMENTS}

We thank Dr. Y. X. Cao, Dr. Dale Braden, and Dr. Jason Perry at Schrödinger Inc. for technical support in using and modifying Jaguar. This research was initiated with funding from National Institutes of Health (Grant No. HD 36385-02) and U.S. DOE (Grant No. ASCI-ASAP) and completed with funding from NSF (CHE and NIRT) and ONR. The facilities of the Materials and Process Simulation Center used in these studies were funded by ONR-DURIP, ARO-DURIP, NSFMRI, IBM-SUR, and the Beckman Institute. In addition, the Materials and Process Simulation Center is funded by grants from DOE-FETL, ARO-MURI, ONR-MURI, NIH, NSF, General Motors, ChevronTexaco, Seiko-Epson, Berlex Pharma, and Asahi Kasei. X.X. is also funded by the National Natural Science Foundation of China (Grant No. 20021002), National Natural Science Foundation of Fujian (Grant No. 2002F010), the Ministry of Science and Technology of China (Grant No. 2001CB610506), and TRAPOYT from the Ministry of Education of China.

${ }^{1}$ R. G. Parr and W. Yang, Density Functional Theory of Atoms and Molecules (Oxford University Press, New York, 1989).

${ }^{2}$ W. J. Hehre, L. Radom, P. V. R. Schleyer, and J. A. Pople, Ab Initio Molecular Orbital Theory (Wiley, New York, 1986).

${ }^{3}$ P. A. M. Dirac, Proc. Cambridge Philos. Soc. 26, 376 (1930).

${ }^{4}$ J. C. Slater, Quantum Theory of Molecules and Solids (McGraw-Hill, New York, 1974), Vol. 4.

${ }^{5}$ S. H. Vosko, L. Wilk, and M. Nusair, Can. J. Phys. 58, 1200 (1980).

${ }^{6}$ R. O. Jones and O. Gunnarsson, Rev. Mod. Phys. 61, 689 (1989).

${ }^{7}$ D. C. Langreth and M. J. Mehl, Phys. Rev. B 28, 1809 (1983).

${ }^{8}$ J. P. Perdew and Y. Wang, Phys. Rev. B 33, 8800 (1986).

${ }^{9}$ A. D. Becke, Phys. Rev. A 38, 3098 (1988).

${ }^{10}$ J. P. Perdew, in Electronic Structure of Solids ' 91 , edited by P. Ziesche and H. Eschrig (Akademie, Berlin, 1991), p. 11.
${ }^{11}$ J. P. Perdew, K. Burke, and M. Ernzerhof, Phys. Rev. Lett. 77, 3865 (1996).

${ }^{12}$ Y. Zhang and W. Yang, Phys. Rev. Lett. 80, 890 (1998).

${ }^{13}$ B. Hammer, L. B. Hansen, and J. K. Norskov, Phys. Rev. 59, 7413 (1999).

${ }^{14}$ C. Adamo and V. Barone, J. Chem. Phys. 116, 5933 (2002).

${ }^{15}$ A. D. Becke, J. Chem. Phys. 84, 4524 (1986).

${ }^{16}$ C. Lee, W. Yang, and R. G. Parr, Phys. Rev. B 37, 785 (1988).

${ }^{17}$ J. P. Perdew and Y. Wang, Phys. Rev. B 45, 13244 (1992).

${ }^{18}$ M. Filatov and W. Thiel, Mol. Phys. 91, 847 (1997).

${ }^{19}$ P. M. W. Gill, Mol. Phys. 89, 433 (1996).

${ }^{20}$ F. A. Hamprecht, A. J. Cohen, D. J. Tozer, and N. C. Handy, J. Chem. Phys. 109, 6264 (1998).

${ }^{21}$ C. Adamo and V. Barone, J. Chem. Phys. 108, 664 (1998).

${ }^{22}$ W.-M. Hoe, A. J. Cohen, and N. C. Handy, Chem. Phys. Lett. 341, 319 (2001).

${ }^{23}$ E. H. Lieb and S. Oxford, Int. J. Quantum Chem. 19, 427 (1981).

${ }^{24}$ M. Levy, Int. J. Quantum Chem. S23, 617 (1989).

${ }^{25}$ A. J. Cohen and N. C. Handy, Chem. Phys. Lett. 316, 160 (2000).

${ }^{26}$ A. D. Becke, J. Chem. Phys. 98, 5648 (1993).

${ }^{27}$ L. A. Curtiss, K. Raghavachari, G. W. Trucks, and J. A. Pople, J. Chem. Phys. 94, 7221 (1991).

${ }^{28}$ L. A. Curtiss, K. Raghavachari, P. C. Redfern, and J. A. Pople, J. Chem. Phys. 106, 1063 (1997).

${ }^{29}$ L. A. Curtiss, P. C. Redfern, K. Raghavachari, and J. A. Pople, J. Chem. Phys. 109, 42 (1998).

${ }^{30}$ M. Rasolt and D. J. W. Geldart, Phys. Rev. B 34, 1325 (1986).

${ }^{31}$ L. J. Sham, in Computational Methods in Band Theory, edited by P. Marcus, J. F. Janak, A. R. Williams (Plenum Press, New York, 1971).

${ }^{32}$ D. C. Langreth and J. P. Perdew, Phys. Rev. B 21, 5469 (1980).

${ }^{33}$ E. K. U. Gross and R. M. Dreizler, Z. Phys. A 302, 103 (1981).

${ }^{34}$ C. Lee and Z. Zhou, Phys. Rev. A 44, 1536 (1991).

${ }^{35}$ L. Kleinman, Phys. Rev. B 30, 2223 (1984).

${ }^{36}$ A. D. Becke, Int. J. Quantum Chem. 23, 1915 (1983).

${ }^{37}$ S. K. Ghosh and R. G. Parr, Phys. Rev. A 34, 785 (1986).

${ }^{38}$ T. Tsuneda, M. Kamiya, N. Morinaga, and K. Hirao, J. Chem. Phys. 114, 6505 (2001)

${ }^{39}$ J. P. Perdew, K. Burke, and Y. Wang, Phys. Rev. B 54, 16533 (1996).

${ }^{40}$ D. J. Lacks and R. G. Gordon, Phys. Rev. A 47, 4681 (1993).

${ }^{41}$ E. Engel and S. H. Vosko, Phys. Rev. A 47, 2800 (1993).

${ }^{42}$ S. J. Chakravorty and E. R. Davidson, J. Phys. Chem. 100, 6167 (1996).

${ }^{43}$ J. F. Ogilvie and F. Y. H. Wang, J. Mol. Struct. 273, 277 (1992).

${ }^{44}$ M. Levy and J. P. Perdew, Phys. Rev. A 32, 2010 (1985).

${ }^{45}$ B. G. Johnson, P. M. W. Gill, and J. A. Pople, J. Chem. Phys. 98, 5612 (1992).

${ }^{46}$ X. Xu and W. A. Goddard III, Proc. Natl. Acad. Sci. USA, 101, 2673 (2004).

${ }^{47}$ J. P. Perdew, K. Burke, and M. Ernzerhof, Phys. Rev. Lett. 80, 891 (1998).

${ }^{48}$ N. Rösch and S. B. Trickey, J. Chem. Phys. 106, 8940 (1997).

${ }^{49}$ T. V. Mourik and R. J. Gdanitz, J. Chem. Phys. 116, 9620 (2002).

${ }^{50}$ J. M. Galbraith and H. F. Schaefer, J. Chem. Phys. 105, 862 (1996).

${ }^{51}$ J. M. Pérez-Jordá and A. D. Becke, Chem. Phys. Lett. 233, 134 (1995).

${ }^{52}$ S. Kristyan and P. Pulay, Chem. Phys. Lett. 229, 175 (1994).

${ }^{53}$ Y. Zhang, W. Pan, and W. Yang, J. Chem. Phys. 107, 7921 (1997).

${ }^{54}$ D. C. Patton and M. R. Pederson, Phys. Rev. A 56, R2495 (1997).

${ }^{55}$ T. A. Wesolowski, O. Parisel, Y. Ellinger, and J. Weber, J. Phys. Chem. A 101, 7818 (1997).

${ }^{56}$ Y. Andersson, D. C. Langreth, and B. I. Lundqvist, Phys. Rev. Lett. 76, 102 (1996).

${ }^{57}$ J. F. Dobson and B. D. Dinte, Chem. Phys. Lett. 76, 1780 (1996).

${ }^{58}$ W. Kohn, Y. Meir, and D. E. Makarov, Phys. Rev. Lett. 80, 4153 (1998).

${ }^{59}$ Q. Wu and W. Yang, J. Chem. Phys. 116, 515 (2002).

${ }^{60}$ K. Kim and K. D. Jordan, J. Phys. Chem. 98, 10089 (1994).

${ }^{61}$ D. A. Estrin, L. Daglieri, G. Corongiu, and E. Clementi, J. Phys. Chem. 100, 8701 (1996).

${ }^{62}$ W. Klopper, J. G. C. M. van Duijneveldt-vande Rijdt, and F. B. van Duijneveldt, Phys. Chem. Chem. Phys. 2, 227 (2000).

${ }^{63}$ A. Bleiber and J. Sauer, Chem. Phys. Lett. 238, 243 (1995).

${ }^{64}$ J. A. Odutola and T. R. Dyke, J. Chem. Phys. 72, 5062 (1980).

${ }^{65}$ W. S. Benedict, N. Gailan, and E. K. Plyler, J. Chem. Phys. 24, 1139 (1956).

${ }^{66}$ L. Fredin, B. Nelander, and G. Ribbegard, J. Chem. Phys. 66, 498 (1977).

${ }^{67}$ B. Nelander, J. Chem. Phys. 69, 3870 (1978).

${ }^{68}$ L. A. Curtiss, D. J. Frurip, and M. Blander, J. Chem. Phys. 71, 2703 (1979). 